\title{
New Arguments for a Central Solomons Family Based on Evidence from Pronominal Morphemes
}

\author{
Toni Pedrós
}

\author{
LEIDEN UNIVERSITY
}

\begin{abstract}
In the Solomon Islands, four Papuan languages are spoken: Savosavo, Touo, Lavukaleve, and Bilua. Some scholars, namely Todd and Ross, have tried to prove that these languages are genetically related through the comparison of pronouns and other morphemes, such as object and subject affixes. Although a similarity in the pronominal forms has been identified, the low number of lexical similarities has not allowed a definitive conclusion on the existence of the family.

In this paper, the pronouns and all other morphemes that carry information on gender, person, or number in each language are compared in order to identify recurrent forms carrying identical gender, person, or number information. These recurring forms are used to perform internal reconstructions in each language, which in turn are used to propose a reconstruction of some pronouns of the putative protolanguage and a family tree. The comparison among the four languages leads to the identification of an identical syncretism in clusivity between first person inclusive and second person nonsingular morphemes, which is expressed with the same form in the four languages. This syncretism, together with the very similar first and second person pronominal paradigms, are adduced as new arguments in favor of the existence of a Central Solomons family.
\end{abstract}

\section{INTRODUCTION ${ }^{1}$}

1.1 THE PAPUAN LANGUAgES OF THE SOLOMON ISLANDS. Savosavo, Touo, ${ }^{2}$ Lavukaleve, and Bilua are the only Papuan ${ }^{3}$ languages that are spoken in the independent country of the Solomon Islands. There are other Papuan languages spoken on Bougainville Island, which is part of the Solomon archipelago but politically

1. I am very much indebted to Marian Klamer for her comments and advice during the whole process of preparing and revising the paper. I am also grateful to Angela Terrill for her comments and encouragement; to Claudia Wegener for her comments on Savosavo and for providing me with an unpublished Savosavo dictionary; and to Kazuko Obata for her comments on Bilua, which have been crucial for a more accurate presentation of the phonetics of some Bilua morphemes. Finally, I must thank two anonymous reviewers, who suggested a radical rewriting of the first version of the paper. Their reviews have enormously improved the paper.

2. Touo is also referred to in the literature as Baniata.

3. The term "Papuan" is used here to refer to the languages spoken in New Guinea and nearby islands that are not Malayo-Polynesian.

Oceanic Linguistics, Volume 54, no. 2 (December 2015)

(C) by University of Hawai' ${ }^{i}$ Press. All rights reserved. 
part of Papua New Guinea. Throughout this article, I will use the term "Solomon Islands" to refer to the political entity and not the archipelago as a whole.

Savosavo is spoken on Savo Island by around 2,500 people (Wegener 2012:1); Touo is spoken in the south of Rendova Island by 1,870 people (Lewis, Simons, and Fennig 2014); Lavukaleve is the language of the Russell Islands and there are approximately 1,700 speakers (Terrill 2003:1); and Bilua is spoken in Vella Lavella Island by about 8,000-9,000 speakers (Obata 2003:1). Map 1 shows the location of these four languages and the Oceanic languages Roviana and Gela, which will also be treated in this article.

1.2 PROPOSALS FOR A CENTRAL SOLOMONS FAMILY. Savosavo, Touo, Lavukaleve, and Bilua have been classified by several scholars as forming a language family called Central Solomons or Central Solomon. According to Terrill (2006:280), "Greenberg (1971) was the first to make an explicit claim for the unity of these languages." He based his claim on the similarity of the pronouns in the four languages (Dunn and Terrill 2012:5). Greenberg's claim “was shortly followed by Wurm's

MAP 1. THE SOLOMONS ARCHIPELAGO SHOWING THE LOCATION OF LANGUAGES DISCUSSED ${ }^{\dagger}$

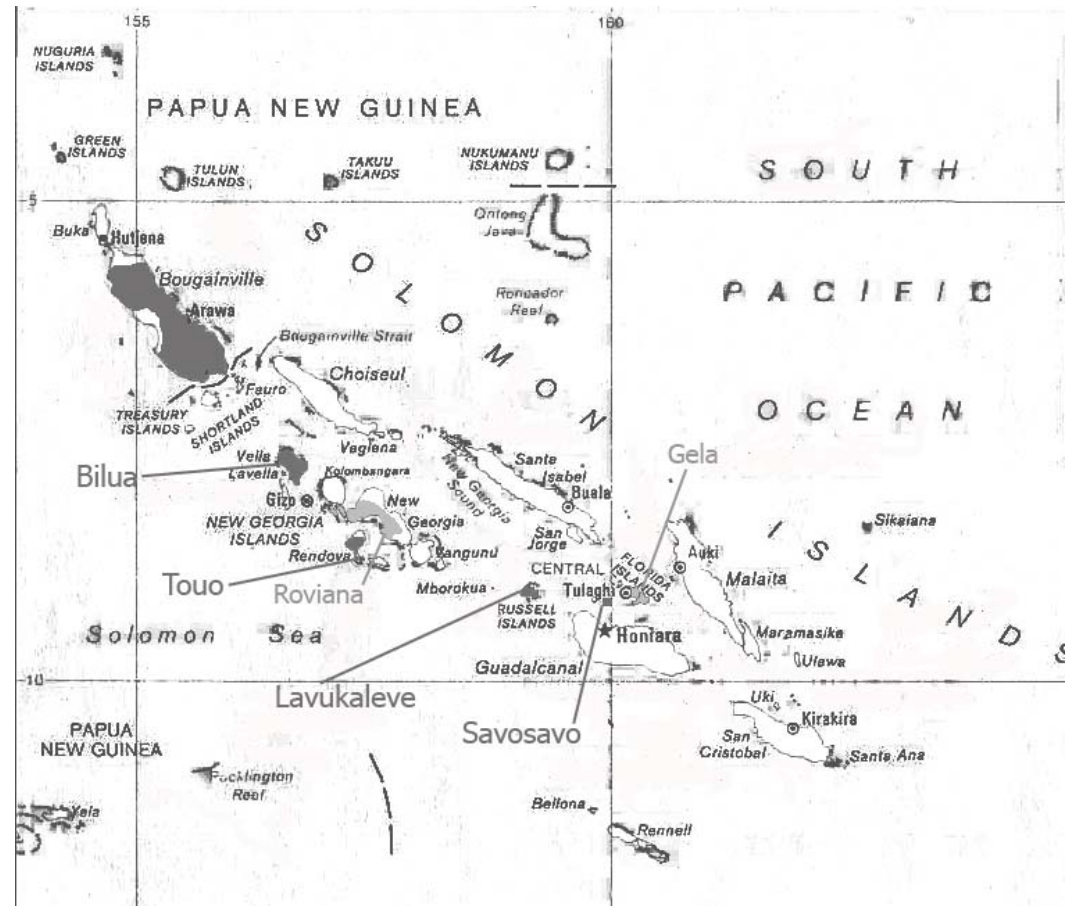

Areas where Papuan languages are spoken are in dark gray, not only in the Solomon Islands, but also in Bougainville (Papua New Guinea). Roviana- and Gela-speaking areas are in light gray. The other languages spoken in the area are all Oceanic. This map is my own work on the basis of a map of the Solomon Islands, courtesy of the University of Texas Libraries, with the location of languages according to Lewis, Simons, and Fennig (2014). 
(1972, 1975, 1982) proposal of an East Papuan phylum, linking all the Papuan languages of the islands off the coast of New Guinea into one genetic grouping" (Terrill 2006:280).

Todd (1975) and Ross (2001) have tried to find the evidence for the family mainly through the comparison of pronouns. Todd (1975) compares (i) pronouns and other morphemes that mark gender, person, or number, and (ii) lexical items. She finds resemblances in the gender, person, and number (GPN) morphemes, but the lexical comparison does not render promising results. Ross (2001) explores the validity of Wurm's East Papuan phylum through the comparison of pronouns, and reconstructs the pronouns of the Central Solomons protolanguage. In Ross (2005), he again uses the pronouns to classify all Papuan languages and, in a classification that he calls "tentative," includes the four Papuan languages of the Solomon Islands in a Central Solomons family. Dunn et al. (2005) carry out a different and novel approach and compare a set of 125 grammatical features. After successfully testing their method against the well-established genealogical tree of some Western Oceanic languages, they apply the same method to Island Melanesian Papuan languages, and the results show that Savosavo, Touo, Lavukaleve, and Bilua are closer to each other than any is to other Papuan languages of the region.

Nonetheless, there are other studies that challenge the existence of the family. Hammarström (2012) analyzes Ross's (2005) methodology and concludes that the similarities found by Ross might be due to chance, due possibly to the small phonological inventories of most Papuan languages. However, Hammarström's article deals mainly with the evidence that Ross provides in favor of the Trans-New Guinea family, namely the coincidences in 1st and 2nd person pronouns. Hammarström's arguments are based on the large number of Papuan languages and the small phonological inventories typical of these languages, which should favor the recurrence of specific consonants in 1st and 2nd person pronouns. These arguments cannot be applied to the Central Solomon languages because they are only four.

Dunn and Terrill (2012) perform a so-called Oswalt Monte Carlo test in order to check lexical similarities among the Central Solomons languages and neighboring Oceanic languages, and the results show that lexical similarities among the four Central Solomons languages are due to massive Oceanic borrowing. However, they give more confidence to the method used by Dunn et al. (2005) - Terrill is among the alii- by stating that "we judge that a false negative in the Oswalt Monte Carlo test is more likely than a false positive in the spatial autocorrelation test on structural features of the language, especially given the archaeological and genetic evidence for long term, intensive interaction in the pre-Austronesian period" (Dunn and Terrill 2012:22).

What these studies show is that a significant similarity among the four languages has been found only in the pronouns. Pronouns are known to be one of the most stable word classes in the world's languages. In fact, the evidence of pronouns has been used to propose distant genetic relationships, such as the Eurasiatic/Nostratic ( $m-t$ for 1 st and 2 nd person pronouns) and the Amerind ( $n-m$ for 1 st and 2 nd person pronouns) hypotheses. Much more nonpronominal vocabulary of common descent, however, has been found in Indo-European languages than in the Central Solomons languages. What this implies is that, if the four Papuan languages of the Solomon Islands are actually related, the relation is very ancient. If pronouns are the only related lexical items that can be found in these 
languages, this means that, since the time that the putative protolanguage existed, almost all the vocabulary except the pronouns has changed; the time elapsed is, thus, so long that the inexorable process of language change has left only the pronouns as words that can show a relation, or the rate of language change has been very fast due to a high interaction with neighboring languages.

Another very stable lexical item is numerals, above all, low numerals. Table 1 provides an overview of the first five numerals in the four Central Solomons languages. At first sight, there appears to be a relation among Savosavo, Touo, and Lavukaleve in the numerals 1 and 2, as well as a similarity in all forms for 3 only in the existence of velar consonants and $/ \mathrm{h} /$, but the relationships are by no means straightforward. For comparison, table 2 shows the same numerals in English, French, and Russian, three representatives of three Indo-European families (Germanic, Romance, and Slavic, respectively). The relation is noticeable at first sight in the numerals 2 and 3, and a relation in 1 can be guessed at. What this shows is that, if the Central Solomons languages are actually related, either the protolanguage is older than Proto-Indo-European or these languages have undergone a very fast rate of language change. In either case, a relation among the four languages is not easy to find, as the existing controversy in the literature demonstrates.

\section{TABLE 1. NUMERALS 1-5 IN THE CENTRAL SOLOMONS LANGUAGES}

\begin{tabular}{llllll} 
& $\mathbf{1}$ & $\mathbf{2}$ & $\mathbf{3}$ & $\mathbf{4}$ & $\mathbf{5}$ \\
Savosavo & 'ela, 'pade/pa & 'edo & i'uißa/i'uia & 'auaßa & 'ara \\
Touo & alo/azo & eli & hie & ạo & sodu \\
Lavukaleve & 'telakom, 'telako & 'lelemal, 'lelaol, & 'eja & nun & 'sie \\
& 'lelauel, 'lemal & & & 'sike, ke \\
Bilua & 'omadeu, 'madeu & 'omuga, 'muga & 'zouke, ke & 'ariku & 'sike \\
\hline$\dagger$ & Note that.. symbolizes breathy voice. & & &
\end{tabular}

TABLE 2. NUMERALS 1-5 IN RUSSIAN, ITALIAN, AND ENGLISH ${ }^{\dagger}$

\begin{tabular}{|c|c|c|c|c|c|}
\hline Russian & $\begin{array}{c}1 \\
a^{\prime} d^{j i n}\end{array}$ & $\begin{array}{c}2 \\
\text { dva }\end{array}$ & $\begin{array}{r}3 \\
\operatorname{tr} \mathrm{ji}\end{array}$ & $\begin{array}{c}4 \\
\operatorname{tg} i^{\prime} \text { tirje }^{j}\end{array}$ & $\begin{array}{c}5 \\
\mathrm{p}^{\mathrm{j}} \mathrm{at}^{\mathrm{j}}\end{array}$ \\
\hline Italian & uno & du.e & tre & 'kwatro & tfinkwe \\
\hline English & W $\Lambda \mathrm{n}$ & tu: & $\theta$ ai: & fo: & farv \\
\hline
\end{tabular}

$\bar{\dagger}$ Adapted from Crowley (1997:166).

1.3 APPROACH AND METHODOLOGY. The lack of related basic vocabulary poses a major problem in finding the evidence that proves the existence of the family. Without related lexical items, no cognates can be found and, therefore, no sound correspondences can be posited in order to build a well-grounded reconstruction of the phonological system of the protolanguage and a set of reconstructed words. This is the reason why the main argument in favor of the common ancestry of these languages is the similarity in their pronoun paradigms, but this argument does not constitute the solid proof that would be needed.

We have seen that Todd (1975) and Ross (2001) have tried to find a relation among the four languages on the basis of the similarity of the pronoun paradigm. In this paper, I will follow a partly similar but partly different approach: I will use not only the pronouns 
in order to find similarities, but also other gender, person, and number (GPN) morphemes. It is well known that full pronouns can be grammaticalized and become agreement affixes, or demonstratives can evolve to become definites or 3rd person pronouns (for extensive information on these processes, see Heine and Kuteva 2004:109-13; Hopper and Traugott 2003). These grammaticalization processes result in different morphemes carrying gender, person, and number information having similar forms. This similarity can actually be observed in the Central Solomons languages, and this will be the point of departure of this paper. In each of the four languages, the pronouns will be compared with other GPN morphemes in order to find similar forms carrying the same GPN information (for example, all Savosavo 1st person pronouns, singular, dual, and plural, except 1NSG.INC, have a form starting with $a$-, which implies a possible relation of $a$ - with 1st person). ${ }^{4}$ In this way, more evidence of relationship can be found than by comparing only the pronouns.

Ross (2001) compares several morphemes with the same GPN combination and proposes a reconstruction of full and bound pronouns in each combination for each language, but does not look for recurrent forms carrying only one piece of grammatical information in common (for example, the Savosavo $a$ - in 1st person morphemes mentioned above). Todd (1975) makes a comparison of different GPN morphemes, but each kind of morpheme is compared separately. In this way, Todd compares, in her own terminology, prenominal particles, postnominal particles, personal pronouns, pronominal subject and object affixes, possessive affixes, and other concord-marking forms. Todd devotes a section to the comparison of each kind of morpheme, and actually realizes the relations among all of them, when she makes statements such as "there is a marked resemblance between these pronominal prefixes and the corresponding independent pronouns in Savosavo, Bilua and Lavukaleve" (referring to object affixes) (Todd 1975:815), or "these suffixes also formally resemble the subject and possessive prefixes" (referring to some verbal suffixes in Lavukaleve) (Todd 1975:818). Indeed, as we will see very clearly in section 2, many of these GPN morphemes show resemblances to other morphemes in the same language. Therefore, why should they be compared separately? If forms that indicate specific GPN values are identified, the comparison among different languages may show relations that cannot be found comparing the same category of morphemes, so that an object prefix in Savosavo can resemble a full pronoun in Touo, although it does not resemble the same object prefix in Touo. This work is carried out in detail in the following pages.

The comparison of the GPN morphemes of the same language is based on the assumption that all morphemes with a similar form and the same meaning in a given language have their origin in a common form that became cliticized and/or affixed. The endeavor to reconstruct ancient forms on the basis of different current forms of a language is known as internal reconstruction. Campbell (1998:201-2) describes the process of internal reconstruction in this way: "Lying behind internal reconstruction is the assumption that the variants (allomorphs) of a morpheme are not original, but that at

4. Abbreviations not found in the Leipzig Glossing Rules are the following: ANI, animate; Bi., Bilua; C, consonant; GPN, gender, person, and number; INAN, inanimate; INC, inclusive; La., Lavukaleve; N1 and N2, neuter 1 and 2; N, nasal consonant; Sa., Savosavo; To., Touo; TR, trial; V, vowel. 
some time in the past each morpheme had but one form (shape) and that the variants known today have come about as the result of changes that the language has undergone in its past. We internally reconstruct by postulating an earlier single form together with the changes - usually conditioned sound changes - which we believe to have produced the various shapes of the morpheme that we recognise in its alternants." The identification of some GPN morphemes with a similar form and the same meaning implies the assumption that they are variants of a single older morpheme. Therefore, after related GPN morphemes are found in each language, I will perform an internal reconstruction. Thereafter, the internally reconstructed GPN morphemes will be compared among the four languages, and this comparison will lead to a reconstruction of the pronouns of a putative Proto-Central Solomons language. However, the problem of the lack of cognates mentioned above does not allow a reconstruction in the strict sense. A reconstruction of the vocabulary of a protolanguage in the strict sense implies that sound correspondences have been found, and the reconstruction is based on these correspondences. Thus, the reconstruction of the pronouns in this article must be regarded as the evolution path from the protopronouns to the current GPN morphemes that I have considered the most probable according to the current forms and the received knowledge of sound changes. This reconstruction is based on the assumption of the existence of the family, which is not a proven fact, and is not based on sound correspondences. Therefore, the reconstruction must be deemed highly tentative or even speculative. It is conceived as a reasonable proposal of how things might have happened, and it is done in the hope that it may encourage future research that may improve it and provide more evidence.

The paper ends with a branching proposal that is based on some facts that seem to point to a split of the protolanguage into two subgroups. This proposal is not based on a set of shared innovations and must, therefore, also be considered highly tentative or even speculative. The goal of the branching proposal is to show some facts that have not been identified in the previous literature and might be a good point of departure for future research on the family structure.

This paper, thus, has two goals. One is to provide arguments in favor of the existence of the family that are more convincing than the mere similarity of pronouns noticeable at first sight. This goal is pursued through a detailed comparison of the GPN morphemes that unveils deeper similarities that have not been shown in the previous literature. Once these similarities have been studied, I will argue why I consider that they cannot be attributable to borrowing or chance. The second goal comes from the conclusion of the first: if these languages are actually related, they are descended from a common protolanguage, which implies that the GPN morphemes with a similar form and the same meaning in the four languages are cognates. The assumption that the similar forms are cognates leads to the reconstruction of the protopronouns paradigm mentioned above, keeping in mind the difficulties explained above. The part devoted to the first goal (sections 2-4) consists of showing facts and arguments in favor of the genetic relatedness of the four languages. The part devoted to the second goal (sections 5 and 6) is a proposal of how the GPN morphemes might have evolved from a protolanguage to the present four languages.

First, in section 2, I present a table of GPN morphemes for each language, describe the relations among the morphemes in each language separately, and carry out an internal 
reconstruction. A different approach is applied to Touo, for which the reconstruction is based on the whole pronoun paradigm. In section 3, the internally reconstructed forms are compared among the four languages in order to find possible cognates. Although pronouns are rarely borrowed, pronoun lists of two Oceanic languages of the Solomon Islands, Roviana and Gela, are provided so as to discard similarities among the Central Solomons languages due to borrowing from Oceanic (see 3.4). The location of Roviana and Gela is shown in map 1, very close to Touo and Savosavo, respectively. Section 4 provides arguments for the genetic relatedness of the four languages on the basis of the similarities found in section 3 .

The reconstruction of the protopronouns is carried out in section 5, and section 6 proposes a family tree. Finally, section 7 provides a summary and some ideas about future research.

Three of these languages (Savosavo, Lavukaleve, and Bilua) have extensive descriptive grammars (Wegener 2012, Terrill 2003, and Obata 2003, respectively). The information on Touo is much scarcer. I have used Todd (1975) for the list of pronouns and, in order to know exactly the phonological value of Todd's orthography, I have consulted Dunn and Terrill (2003). In this regard, I have used for all languages a strict IPA notation. This is the only way to make a reliable comparison: comparisons using different orthographies may be misleading. Thus, I have adapted the GPN forms of each author according to the phonological descriptions given by them, with the exception of Touo, where the forms are from Todd (1975) and the phonological description from Dunn and Terrill (2003).

For each table illustrating GPN morphemes, a very short description of the functions of every morpheme is given in the footnotes. The interested reader will find extensive information in the works given as references.

\section{GENDER, PERSON, AND NUMBER MORPHEMES}

\subsection{SAVOSAVO}

2.1.1 Relations among GPN morphemes. Savosavo GPN morphemes are shown in table 3, for which all the information has been drawn from Wegener (2012). The following relations have been identified: ${ }^{5}$

Sa.1. $-n$-occurs in the 1 SG free pronoun, subject enclitic, and possessives, and also in all 1st person forms of the object affixes and postpositions. Therefore, $-n$ - marks 1 st person.

Sa.2. The alternation $-\beta a /-m a$ for masculine/feminine occurs in several morphemes: possessives, ${ }^{6}$ genitive case, and 'la $\beta a$. In the genitive case, $-\beta a$ also expresses nonsingular, and in 'la $\beta a, 1 \mathrm{SG}$ and $2 \mathrm{SG}$. Therefore, $-\beta a$ and $-m a$ indicate masculine and feminine gender, respectively, and in some cases, the feminine form is restricted to 3SG.F, while the masculine form can express number and person values for both genders.

Sa.3. Most morphemes with the same GPN combination have similar forms. These forms are $n o / n$ for $2 \mathrm{SG}, l o / l$ for $3 \mathrm{SG} . \mathrm{M}, \mathrm{ko} / \mathrm{mo} / \mathrm{k} / \mathrm{m}$ for $3 \mathrm{SG} . \mathrm{F}, \mathrm{m} / \mathrm{m}$ for $1 \mathrm{DU} . \mathrm{EXC}$ and all dual forms with 'laßa, pe/p for 2DU, to/t for 3DU, $\beta e / \beta$ for 1PL.EXC, $m e / m$ for 2PL, ze/za/z for 3PL. 1SG is explained in Sa.1 and 1NSG.INC in Sa.4.

5. In order to facilitate cross-referencing, I label each relation with a language abbreviation and a numeral: thus, Sa.1 is relation 1 in Savosavo, To. 2 is relation 2 in Touo, and so on

6. Here I consider $-a$, present in the possessives, as a development of $-\beta a$ through elision of $/ \beta /$. 
Sa.4. The 1NSG.INC form mai in free pronouns, possessives, and postpositions is made up of 2PL me plus 1SG ai, while the 1NSG.INC object suffix -mini is formed by the addition of the object suffixes for 2PL -mi and 1SG -ni. This construction makes sense, given that 1NSG.INC signals you and me, that is, 2nd person + 1SG. The 1NSG subject enclitic is $=m e$, which suggests that the 1SG morphemes were added to this already existing form.

Sa.5. The 1st person forms of all the full pronouns except 1NSG.INC begin with $a$ Therefore, $a$ - seems to be marking exclusivity, given that the 1SG is exclusive because of the very fact of being singular and 1st person.

Sa.6. All object affixes end with $-i$.

TABLE 3. SAVOSAVO GPN MORPHEMES ${ }^{\dagger}$

\begin{tabular}{|c|c|c|c|c|c|c|c|c|c|c|}
\hline & $\begin{array}{l}\text { FREE } \\
\text { PRO }\end{array}$ & SUB.ENC & OBJ.AFF & POSS & DET & $\begin{array}{l}\text { NOM. } \\
\text { CASE }\end{array}$ & $\begin{array}{l}\text { GEN. } \\
\text { CASE }\end{array}$ & 'LA $\beta \mathrm{A}$ & POSTP & $\begin{array}{l}\text { NUM. } \\
\text { ENC }\end{array}$ \\
\hline $1 \mathrm{SG}$ & $\begin{array}{l}\text { a'ji, } \\
\text { ai }^{*}\end{array}$ & $=$ ne & n-, -ni & $\begin{array}{l}\text { a'nia, } \\
\text { a'nima }\end{array}$ & - & $=$ na & - & & $\mathrm{n}-$ & - \\
\hline $2 \mathrm{SG}$ & no & $=$ no & n-, -ni & $\begin{array}{l}\text { no'noa, } \\
\text { no'noma }\end{array}$ & - & & - & $-\beta a$ & n- & - \\
\hline 3SG.M & lo, la & $=10$ & $1-,-1 i$ & $\begin{array}{l}\text { lo'loa, } \\
\text { lo'loma }\end{array}$ & lo & & $-\beta a$ & & $1-$ & $\varnothing$ \\
\hline 3SG.F & ko, ka & $=$ чцо & k-, -ui & $\begin{array}{l}\text { ko'koa, } \\
\text { ko'koma }\end{array}$ & ko, koi & $=$ kona & $-m a$ & $-m a$ & $\mathrm{k}-$ & \\
\hline 1DU.EXC & 'aue & $=$ uе & n-, -щini & $\begin{array}{l}\text { a'uea, } \\
\text { a'uema }\end{array}$ & - & $=$ na & 7 & -ще & аше n- & - \\
\hline $2 \mathrm{DU}$ & pe & $=$ pe & p-, -pi & $\begin{array}{l}\text { pe'pea, } \\
\text { pe'pema }\end{array}$ & - & & - & & p-/pe- & - \\
\hline $3 \mathrm{DU}$ & to, ta & $=$ to & $\mathrm{t}-,-\mathrm{ti}$ & $\begin{array}{l}\text { to' toa, } \\
\text { to' toma }\end{array}$ & to & $=$ tona & $-\beta a$ & & t- & $=(\mathrm{za}) \mathrm{lo}$ \\
\hline 1PL.EXC & 'aße & $=\beta \mathrm{e}$ & $\mathrm{n}-,-\beta$ ini & $\begin{array}{l}\text { a'ßea, } \\
\text { a'ßema }\end{array}$ & - & $=$ na & - & & $\mathrm{a} \beta \mathrm{e}$ n- & - \\
\hline 1NSG.INC ${ }^{\dagger \dagger}$ & mai & $=\mathrm{me}$ & n-, -mini & $\begin{array}{l}\text { 'maia, } \\
\text { 'maima }\end{array}$ & - & & - & & mai n- & - \\
\hline $2 \mathrm{PL}$ & me & $=\mathrm{me}$ & $\mathrm{m}-,-\mathrm{mi}$ & $\begin{array}{l}\text { me'mea, } \\
\text { me'mema }\end{array}$ & - & & - & -me & m-/me- & - \\
\hline $3 \mathrm{PL}$ & $\begin{array}{l}\text { ze, za, } \\
\text { zepo, }\end{array}$ & $=\mathrm{ze}$ & $\mathrm{z}-,-\mathrm{mi}$ & $\begin{array}{l}\text { ze'zea, } \\
\text { ze'zema }\end{array}$ & lo & & $-\beta a$ & & z-/ze- & $=$ uца \\
\hline
\end{tabular}

$\dagger \quad$ Adapted from Wegener (2012). Explanations for column headings are:

FREE PRO. Free pronouns: They can receive case suffixes (Wegener 2012:77).

SUB.ENC. Subject enclitics: They are Wackernagel enclitics, i.e., they are attached to the first constituent of the clause (Wegener 2012:79).

OBJ.AFF. Object affixes: Some verbs take prefixes, some take suffixes, and some take both (Wegener 2012:50-55).

POSS. Possessives.

DET. Determiners: They are preposed to the head noun (Wegener 2012:84).

NOM.CASE. Nominative case: Only 3SG.F and 3DU have a form different from the general $=n a$ (Wegener 2012:135)

GEN.CASE. Genitive case: In 3SG, $-\beta a$ and - $m a$ indicate masculine and feminine, respectively (Wegener 2012:137).

'LAßA. 'Laßa is defined as a "proprietive marker" (Wegener 2012:98)

POSTP. Postpositions: There are three of these, but all are inflected with the same prefixes: $l$ aka 'with', l-omata 'at', and l-omiti 'for' (Wegener 2012:105-8).

NUM.ENC. Number enclitics: They are used to mark dual or plural number on noun phrases

when the head of the noun phrase does not inherently mark number (Wegener 2012:127).

\pm The form with - ma is feminine, that with $-\mathrm{a}$ is used elsewhere (Wegener 2012:80-81).

\# The form ai is used with the genitive suffix (Wegener 2012:77-78).

$\dagger$ The 1DU.INC and 1PL.INC forms are identical, which is why I label this form 1NSG.INC. 
2.1.2 Internal reconstruction. The form $-n$ - occurring in 1st person morphemes appears as $-n i,=n e$, or just $n$-. $=n e$ is consistent with the other subject enclitics in that all of them are formed by a consonant plus $-e$ or $-o$, and $-n i$ is consistent with the other object affixes because all of them end in $-i$. The $1 \mathrm{SG}$ pronoun $a$ ' $i$ is formed with $a$-, identified in Sa.5 as marking exclusivity. In this way, the 1SG, 1DU.EXC, and 1PL.EXC pronouns seem to be formed with the addition of $a$ - plus - $n i,-u e$, and - $\beta e$, respectively. - $-\mu e$ is also the form for all dual morphemes in 'laßa. The forms $-n i$ and $n$ - occur in object affixes and postpositions, respectively, in all 1st person morphemes, and in both instances, the 1NSG forms are built with the addition of other morphemes that differentiate them from the 1SG forms. Thus, the whole set of morphemes with $-n$ - suggests that they are built on the basis of the form $-n i$, given that $-i$ in the full pronoun $a^{\prime}$ ni does not appear to be related to any other full pronoun. Accordingly, I will posit the current form a'ni as the reconstructed 1SG pronoun. Due to the position of stress in 'ame and 'aße, I will posit it without stress position, just as *ani. I reproduce in table 4 these three pronouns with a hyphen separating $a$ - in order to indicate that it is an exclusive marker.

The groups of forms described in Sa.3 must be reconstructed with the form bearing the vowel, given that it is lost when affixed. In the case of 3SG.F ko/mo/k/u, the reconstructed form is *ko, given that $/ \mathrm{k} /$ becomes $/ \mathrm{ur} /$ in the subject enclitic $=u o$ and in the object affix -ui in both cases between vowels - Savosavo syllable structure is $(\mathrm{C}) \mathrm{V}$ (Wegener 2012:23) — while, in the possessives ko 'koa and ko 'koma, /k/ remains unchanged, probably because it is a reduplication. Regarding the pronouns that have alternative forms with $-a$ (3SG.M la, 3SG.F ka, 3DU ta, and 3PL $z a$ ), Wegener (2012:77) says that "they can only be used in some syntactic contexts and, in those contexts, have a connotation of proximity." Given their special function, the forms with $-e$ or $-o$ are preferred for the reconstruction.

I have described the 1NSG.INC morphemes mai and -mini as a union of a 2PL and a 1SG morpheme - see Sa.4 in the previous section - and have pointed to the subject enclitic $=m e$ as a form to which no 1SG form was added. What these morphemes suggest is that the 1SG forms $a i$ and -ni were added to a preform *me, to which no new phonetic material was added in the subject enclitic. Therefore, the posited 1NSG.INC pronoun is *me.

With all this, the proposed preforms are shown in table 4 .

\subsection{TOUO}

2.2.1 Relations among GPN morphemes. In Touo, the GPN morphemes found in Todd (1975) are full pronouns, object suffixes, indefinite articles, and near demonstra-

TABLE 4. RECONSTRUCTED PRE-SAVOSAVO PRONOUNS

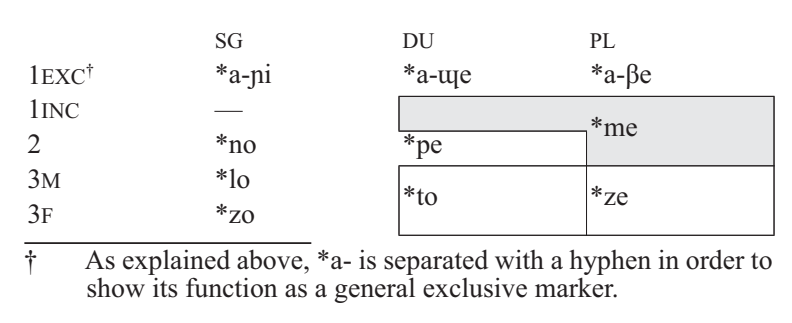


tives (her own terminology). I will show here all the paradigms, but will concentrate mainly on the pronouns. The reasons for this are (i) that the existence of four numbers and four genders (at least in 3SG) in Touo makes the pronoun table very large; (ii) there are very few object suffixes, and a comparison of them with pronouns does not yield interesting results; and (iii) indefinite articles form a paradigm, together with demonstratives, with an obvious regularity and correlation with $3 \mathrm{rd}$ person pronouns. However, the table of pronouns shows a striking symmetry and a matrix of relations that deserves a thorough study. The paradigms are shown in table 5 (object suffixes, indefinite article, and near demonstratives) and in table 6 (full pronouns). ${ }^{7}$

The functions of the different parts of the pronouns that have been identified are as follows: To.1. $e$ - is acting as an exclusive marker, given that it occurs in all exclusive forms (including singular, which is exclusive because of the very fact of being first person and singular).

To.2. $z$ - occurs as a 3M marker only in singular and dual. $-z o$ also appears as SG.M in the indefinite article and near demonstratives.

TABLE 5. TOUO OBJECT SUFFIXES, INDEFINITE ARTICLES, AND NEAR DEMONSTRATIVES ${ }^{\dagger}$

\begin{tabular}{|c|c|c|c|c|c|c|c|}
\hline \multicolumn{4}{|c|}{ OBJECT SUFFIXES } & \multirow{3}{*}{$\begin{array}{l}\text { SG.M } \\
\text { SG.F }\end{array}$} & \multirow{2}{*}{$\begin{array}{l}\text { IND.ART. } \\
\text { azzo }\end{array}$} & \multirow{2}{*}{$\begin{array}{l}\text { DEM.1 } \\
\text { ndezo }\end{array}$} & \multirow{2}{*}{$\begin{array}{l}\text { DEM.2 } \\
\text { "gezo }\end{array}$} \\
\hline & SG & DU & PL & & & & \\
\hline $1 \mathrm{INC}$ & - & \multirow{3}{*}{-na } & & & ạma & ${ }^{n}$ demi & "gemi \\
\hline $1 \mathrm{EXC}$ & & & & \multirow{4}{*}{$\begin{array}{l}\text { SG.N1 } \\
\text { SG.N2 } \\
\text { PL.M } \\
\text { PL.F } \\
\text { PL.N }\end{array}$} & ana & ${ }^{n}$ dena & ¡gena \\
\hline 2 & & & & & ango & ${ }^{\mathrm{n}} \mathrm{den} \mathrm{O}$ & "geno \\
\hline $3 \mathrm{M}$ & $-\mathrm{v}$ & -Ia & -ma & & ạmo & ndemo & "Igems \\
\hline $3 \mathrm{~N}$ & & 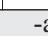 & & & ano & ${ }^{\mathrm{n}} \operatorname{den} \boldsymbol{}$ & "geno \\
\hline
\end{tabular}

$\dagger \quad$ According to Todd (1975:825), demonstratives 2 are used with genitive constructions, demonstratives 1 elsewhere.

$\$ \quad$ Indefinite article.

TABLE 6. TOUO FULL PRONOUNS

\begin{tabular}{|c|c|c|c|c|}
\hline & SG & DU & TR & PL \\
\hline 1EXC.M & \multirow{2}{*}{ ẹi } & ẹle & $e^{\mathrm{m}}$ beno & \multirow[t]{2}{*}{$e^{\mathrm{m}} \mathrm{b} 0$} \\
\hline 1EXC.F & & ẹle $\mathrm{e}^{\mathrm{m}} \mathrm{be}$ & $e^{\mathrm{m}}$ benu & \\
\hline 1INC.M & - & mbe & mens & mems \\
\hline 1INC.F & - & ${ }^{m} \mathrm{be}^{\mathrm{m}}$ be & menu & \\
\hline $2 \mathrm{M}$ & \multirow{2}{*}{ noe } & mbele & $\mathrm{me}^{\mathrm{m}}$ ben & \multirow{2}{*}{$m e^{m} b o$} \\
\hline $2 \mathrm{~F}$ & & mbelembe & $\mathrm{me}^{\mathrm{m}}$ benu & \\
\hline $3 \mathrm{M}$ & zo & zele & nวmว & \multirow{2}{*}{ mo } \\
\hline $3 \mathrm{~F}$ & vo & Iombe & nums & \\
\hline $3 \mathrm{~N} 1$ & na & \multirow{2}{*}{$\mathrm{Ie}^{\mathrm{n}} \mathrm{de}$} & \multirow{2}{*}{ nafi } & \multirow{2}{*}{ no } \\
\hline $3 \mathrm{~N} 2$ & yo & & & \\
\hline
\end{tabular}

7. Given that the data in tables 5 and 6 are taken from Todd's (1975) article, no further grammatical description can be given of Touo GPN morphemes. Phonological values are according to Dunn and Terrill (2003). 
To.3. $n-/ \eta-/{ }^{n} d-$ occur in all $3 \mathrm{~N}$ forms. All these phonemes are nasal or nasalized, and all but one are apical. ${ }^{8}-n a$ and $-\eta \supset$ also appear in the indefinite article and near demonstratives expressing SG.N1 and SG.N2, respectively, the same as the full pronouns $n a$ and $\eta$.

To.4. In the dual number, we find two kinds of markers: a general one (le//l-), occurring in all dual forms except 1INC; and $-^{m} b e$, occurring in all DU.F forms (this ${ }^{-m}$ be is the final syllable of all DU.F pronouns and not the ${ }^{m}$ be treated in To. 8 below).

To.5. $n s$ and $n u$ mark masculine and feminine, respectively, in trial number. They appear in all trial masculine and feminine forms.

To.6. me- occurs in all trial and plural forms of $1 \mathrm{INC}$ and 2 nd person.

To.7. $-\supset$ appears in all plural forms. This vowel seems to be related to the indefinite articles and near demonstratives PL.M/PL.F - $m s$ and PL.N $-m$. This relation is based on the fact that 1EXC.PL $e^{m} b s$ and 2PL $m e^{m} b s$ may be considered a development of $*^{*} e^{m}$ bemo and *membemo, respectively, given that the repetition of labial sounds in the same word may easily have led to the current pronouns. In this way, $-m \supset$ would be present in all nonneuter plural pronouns, while $n o$ is the PL.N pronoun. Besides the plural forms, $-m s$ also occurs in 3TR.M and 3TR.F.

To.8. Possibly the first thing that catches the reader's attention when examining table 6 is the widespread occurrence of ${ }^{m} b e$. It shows a certain symmetry in the table, but its role is difficult to ascertain because it is not totally symmetrical. It might be the case that its distribution is due to historical developments that make it impossible to assign it a specific role on the basis of its present form; more concretely, it might be related to $m e$. In the next section, an internal reconstruction is performed in order to explain the current asymmetrical distribution as the evolution of a former symmetrical one.

2.2.2 Internal reconstruction. First of all, I will try to explain the widespread occurrence of ${ }^{m} b e$, identified in To.8 above, with a reconstruction of the pronouns in which this form is present. This is a reconstruction in which the whole system of nonsingular first and second person pronouns is involved.

${ }^{m}$ be occurs in 1INC.DU, 1EXC.TR, 2DU, and 2TR. ${ }^{9}$ These occurrences show a syncretism between 1INC and 2nd person in dual, and between 1EXC and 2nd person in trial. Another syncretism between 1INC and 2nd person can be observed in $m e$ - in trial and plural. Thus, the distribution of ${ }^{m} b e$ is asymmetrical in that its repetition in several pronouns does not allow us to assign it a clear function, while $m e$ - shows a certain symmetry. An internal reconstruction should provide a system of a former stage with pronouns being formed by parts in which grammatical information should be more clearly observed than in the present stage, that is, a more symmetrical or regular system. The assumption is that phonetic change caused a break in the regularity of the system. Thus, the present distribution of pronouns should be reasonably derivable from this reconstructed system according to received wisdom on sound change. This former symmetrical system is proposed in table 7: forms without asterisks represent the current pronouns.

8. Phonemes named dental/alveolar/postalveolar in the IPA chart are referred to as apical by Dunn and Terrill (2003:180).

9. Note that, in To.4, I have considered the $-^{m} b e$ occurring at the end of all DU.F pronouns as a dual feminine marker independent of the ${ }^{m}$ be treated here. 


\section{TABLE 7. PROPOSED INTERNAL RECONSTRUCTION OF TOUO 1ST AND 2ND PERSON PRONOUNS}

\begin{tabular}{|c|c|c|c|c|}
\hline & SG & DU & TR & PL \\
\hline $\begin{array}{l}\text { 1EXC.M } \\
1 \text { EXC.F }\end{array}$ & ẹi & $\begin{array}{l}\text { ẹle } \\
\text { *elleme }\end{array}$ & $\begin{array}{l}\text { *eñ } \\
\text { *ẹnu }\end{array}$ & *emo \\
\hline $\begin{array}{l}\text { 1INC.M } \\
\text { 1INC.F }\end{array}$ & - & $\begin{array}{l}\text { *me } \\
*_{\text {meme }}\end{array}$ & $\begin{array}{l}\text { meno } \\
\text { menu }\end{array}$ & mems \\
\hline $\begin{array}{l}2 \mathrm{M} \\
2 \mathrm{~F}\end{array}$ & noe & $\begin{array}{l}\text { *mele } \\
\text { *meleme }\end{array}$ & $\begin{array}{l}\text { *memens } \\
\text { *memenu }\end{array}$ & *memems \\
\hline
\end{tabular}

The pronouns in table 7 are distributed symmetrically. *me(-) forms a syncretism between 1INC and 2nd person, the 1DU.INC.F pronoun is formed through reduplication of 1DU.INC.M, and this reduplicated *-me has also been extended to mark DU.F in 1EXC and 2nd person. The 1TR.INC and 1PL.INC pronouns are formed with the 1DU.INC.M *me plus the suffixes $-n s,-n u$, and $-m s$, identified as TR.M, TR.F, and plural markers, respectively, in To.5 and To.7. The 2TR and 2.PL pronouns are built through reduplication of *me- with respect to 1TR.INC and 1PL.INC. The 1EXC pronouns are formed through addition of suffixes to *e- (To.1): the dual marker *-Ie (To.4), the trial markers masculine *-no and feminine *-nu (To.5), and the plural marker *-mo (To.7).

The historical development that should have led from the reconstructed table 7 to the current table 6 would have started with a slight phonetic change followed by a chain of analogies. The main change posited is from $/ \mathrm{me} /$ to $/ \mathrm{m} \mathrm{be} /$ in some pronouns and changes due to analogy among pronouns with some GPN information in common. One example of the possible steps of this evolution is as follows:

(a) A phonetic change would have taken place in the forms with the sequence *meme, which may easily have led to the present $m e^{m} b e$ due to the avoidance of repetition of /me/ in two consecutive syllables. This change would have given 1DU.INC.F ${ }^{*}$ me ${ }^{m}$ be, 2TR.M mem ${ }^{m}$ ens, 2TR.F mem $e^{m}$ enu, and 2PL *membems.

(b) Analogy based on the 2TR and 2PL pronouns would have extended the use of ${ }^{m} b e$ to the 1TR.EXC and 1PL.EXC pronouns, giving 1TR.EXC.M $e^{m} b e n s, 1$ TR.EXC.F $e^{m} b e n u$, and 1PL.EXC $e^{m}$ bemo.

(c) Analogy with 1DU.INC.F *membe would have changed the DU.F marker *-me in $1 \mathrm{EXC}$ and 2 nd person to ${ }^{m} b$, giving 1DU.EXC.F ele $e^{m} b e$ and 2DU.F *melembe.

(d) 1DU.INC.F *membe may easily have changed to ${ }^{m} b e^{m} b e$, and analogy would have caused the changes 1DU.INC.M *me $>$ mbe, 2DU.M *mele $>$ mbele and 2DU.F $*_{\text {mele }}$ be $>m$ bele $e^{m} b e$.

(e) 1EXC.PL *en ${ }^{\mathrm{m}}$ bem $e^{m} b s$ and $m e^{m} b s$ through the loss of *-em- (already mentioned in To.7).

As noted above, the basic idea is the change from $/ \mathrm{me} /$ to $/ \mathrm{mbe} /$ and its extension through analogy. The steps proposed here are only meant to be an illustration of how this might have taken place, and other explanations might also be quite feasible. In fact, some of the changes proposed above might have taken place simultaneously, and their order need not necessarily be as is shown here (for example, steps 2, 3, and 4 might change places without altering the results; steps 1 and 4 might have taken place simultaneously, and so on). Another possibility would be the extension of $/ \mathrm{me} /$ through analogy and a 
later general change to /mbe/ in many pronouns, a reverse evolution of the steps proposed above that posit a change * me $>$ mbe and a later extension through analogy.

The occurrence of ${ }^{m} b e$ in table 6 is complex. Thus, the reconstruction proposed above may be improved or even radically changed. This reconstruction departs from a more regular situation in which the pronouns could be divided into parts carrying specific GPN values and from which the current pronouns may have developed through feasible sound changes.

The reconstructions of other Touo forms are more straightforward. The 3M pronoun has two related forms in singular $(z o)$ and dual $(z e l e)$. The reconstructed form must be *zo, given its occurrence isolated in a word as a pronoun and as a suffixed form in the indefinite article and demonstratives (To.2).

The coincidence of $3 \mathrm{~N} 1 n a$ and $3 \mathrm{~N} 2 \eta \supset$ as pronouns, indefinite article, and demonstratives makes them the best possible reconstructed forms in spite of possible relationships with nasals in neuter pronouns described in To.3.

Regarding the dual markers described in To.4, the general one must be reconstructed as *Ie, given that only 3DU.F shows the different form .lo-. The feminine dual marker ${ }^{m} \mathrm{be}$ has already been considered a reduplication in the reconstruction of the 1st and 2nd person paradigm performed above.

The plural markers described in To.7 can be considered as animate $m s$ and inanimate $n s$, due to the fact that $m s$ occurs in all nonneuter plural pronouns (according to historical explanation provided in To.7), indefinite article, and demonstratives, while $m$ is the 3PL.N pronoun and appears suffixed in the indefinite article and demonstratives. The fact that one form is used for masculine and feminine and the other for neuter clearly suggests a division between animate and inanimate.

The trial markers masculine $-n s$ and feminine $-n u$ show no variation among the different pronouns, so that any reconstruction must be identical with the modern forms.

With all this in mind, the proposed reconstruction of Pre-Touo GPN morphemes in table 8 represents not only pronouns, but also morphemes that are combined to build the pronouns. The nonasterisked forms reflect current forms that show no variation.

TABLE 8. RECONSTRUCTED PRE-TOUO GPN MORPHEMES

\begin{tabular}{|c|c|c|c|c|c|c|}
\hline $1 \mathrm{INC} / 2 \mathrm{NSG}$ & *me & DU & $* \mathrm{Ie}$ & PL.ANI *m॰ & 3SG.M & $*_{\mathrm{zo}}$ \\
\hline EXC & e- & TR.M & no & PL.INAN no & 3SG.N1 & na \\
\hline DU.F & *-me (reduplication) & TR.F & nu & & 3SG.N2 & yo \\
\hline
\end{tabular}

\subsection{LAVUKALEVE}

2.3.1 Relations among GPN morphemes. Lavukaleve, like Savosavo, has many GPN morphemes whose forms are related (see table 9): it has no 3rd person pronouns, but their role is fulfilled by demonstratives. The relations among all GPN morphemes are as follows:

La.1. $\eta a-$ occurs as a pronoun and as an object prefix in 1SG.

La.2. The related 2SG forms - $n$ / $y o-$ - $n e$ - occur as a pronoun and as subject and object prefixes.

La.3. $i$ - appears in all 2 nd person pronouns. In 2DU and 2PL, it also appears as a suffix $(-i)$. In both instances, the combination $i-+-i$ is added to the corresponding dual and plural forms in 1INC. 
La.4. The demonstratives seem to be built on a combination of forms, each carrying a piece of grammatical information. In this way, $-n a$ occurs in all masculine forms, $-h-$ in all distal and unspecified feminine demonstratives, $-a$ - in all distal and unspecified nonfeminine demonstratives, $-\imath a-$ in all neuter forms, and $-\beta a$ in the plural forms (also as $\beta$ or - $b a$ in the object prefix, the agreement suffix, the present subject agreement, and the imperative suffix). Besides these forms indicating gender or number, each class of demonstrative has identifying forms: - $O$ - for all but distal, $-e$ - for distal, and $-i$ - for distance-neutral.

La.5. le/lo/la/l occurs in most dual morphemes, meaning that it is clearly a dual marker. La.6. me/m occurs in all 1INC and 2NSG morphemes. The 1DU.INC pronoun is formed with the addition of me plus the dual marker $l$ described in La.5, and 2DU and 2PL pronouns receive the 2 nd person marker $i-+-i$ described in La.3. The dual marker $l$ is also added to the $2 \mathrm{DU}$ pronoun.

La.7. All 1NSG.EXC morphemes are formed with $e$. Therefore, $e$ marks exclusivity.

TABLE 9. LAVUKALEVE GPN MORPHEMES ${ }^{\dagger}$

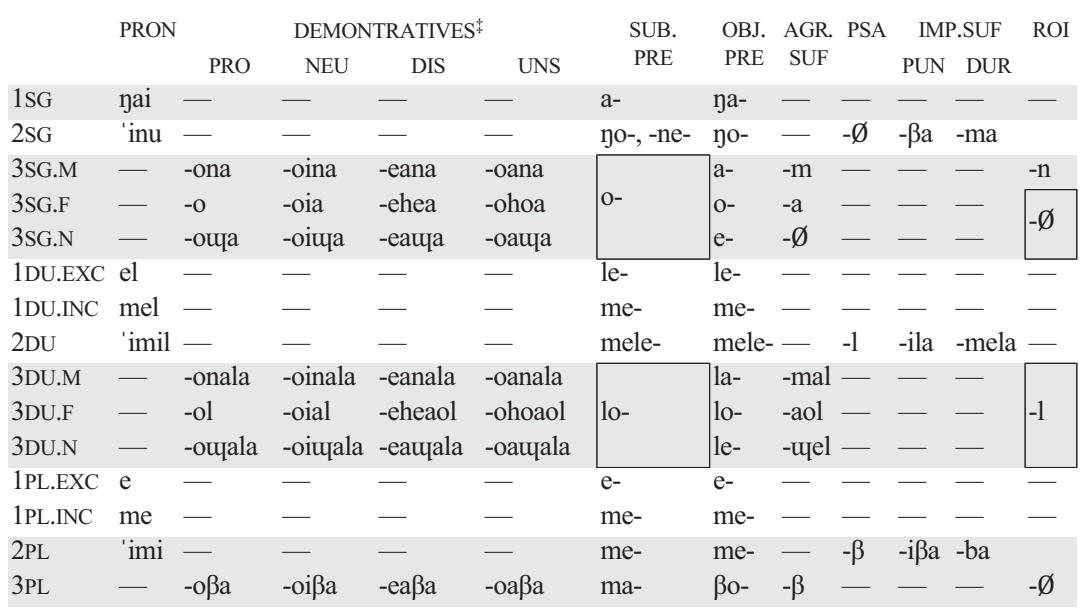

$\dagger \quad$ Adapted from Terrill (2003). Explanations for column headings are: PRON: Pronouns (Terrill 2003:170)

SUB.PRE: Subject prefixes. The 2SG form -ne- is only used when it is the second prefix in a predicate (e.g., if an object prefix is present) (Terrill 2003:243).

OBJ.PRE: Object prefixes (Terrill 2003:243).

AGR.SUF: Agreement suffix. This marks number and gender of a core argument in certain grammatical environments (Terrill 2003:251-52).

PSA: Present subject agreement, marks present tense and number of subject.

IMP.SUF: Imperative suffix: punctual (PUN) and durative (DUR). The punctual is for actions that can be carried out instantaneously, the durative for actions expected to take some time for their completion. The imperative always refers to the 2 nd person and marks number (Terrill 2003:339-40).

ROI: Roi- means 'which' in questions. It marks number and gender of the referent (Terrill 2003:458).

* Demonstratives: proximal (PRO), neutral (NEU), distal (DIS), and unspecified (UNS). This paradigm is used by three demonstratives that Terrill names according to their 3SG.F neutral form: foia, hoia, and oia. Foia functions as a nominal head, hoia is a modifier, and oia has a discourse tracking function (Terrill 2003:172, 177, 183-84). 
La.8. The alternation $a-/ o-/ e$ - for masculine/feminine/neuter occurs in 3SG and 3DU object prefixes and also in the dual agreement suffix. The form $o$ for feminine also occurs in the 3SG and 3DU subject prefixes, which are not marked for gender. This correlation seems to indicate a use of the feminine gender for masculine and neuter referents.

2.3.2 Internal reconstruction. The 1SG pronoun yai has a similar 1SG morpheme only in the object prefix ya- (La.1). It is likely that the object prefix lost/i/ because of the very fact of being a prefix, so that the 1SG preform must be the same as the pronoun: *yai.

The 2SG morphemes shown in La.2 are more problematic. Their forms are the pronoun 'inu, the object prefix $y o-$, and the subject prefixes $y o$ - and -ne-. As is explained in the first footnote to table 9,-ne- only occurs when it is the second prefix in a predicate (for example, if an object prefix is present) (Terrill 2003:243); that is why I have written it with two hyphens before and after the prefix, because it always occurs surrounded by other morphemes in a predicate. The distribution of the four forms suggests a preform * yo or *no. 'inu may derive from an old *ino, and the change from $/ \mathrm{o} /$ to $/ \mathrm{u} /$ may easily have taken place under the influence of the preceding $/ \mathrm{i} /$. The explanation of the change from $/ \mathrm{o} /$ to /e/ in -ne- is not so straightforward, but the fact of being surrounded by more phonetic material in the same word might be a reason for the change. But the main question is whether the nasal of the preform was $/ \mathrm{n} /$ or $/ \mathrm{l} /$. Either *no changed to $\eta o$, or * yo changed to a pronoun *iju and a subject prefix *-ne-, which later shifted from $/ \mathrm{y} /$ to $/ \mathrm{n} /$, giving the current forms 'inu and -ne-. Although both might be possible, a change from $/ \mathrm{n} /$ to $/ \mathrm{n} /$ is more likely. This is a rather common change in the world's languages, and being next to front vowels like /e/ and /i/ may be a reason to cause a shift from a velar to an alveolar nasal. Another reason might be found in the distribution of the combinations of nasals and vowels in Lavukaleve, given that it may show a phonotactic tendency of this language. In the list of 210 words of the Austronesian Basic Vocabulary Database (Greenhill, Blust, and Gray 2008; source for Lavukaleve is Tryon and Hackman 1983), the occurrence of word-medial (intervocalic) combinations of $/ \mathrm{n} /$ and $/ \mathrm{h} / \mathrm{with} / \mathrm{e} /$ and $/ \mathrm{u} / \mathrm{are}$ : $/ \mathrm{ne} / \mathrm{one}, \mathrm{nu} /$ three, and /ye/ or /yu/ zero; the occurrence of word-initial nonlabial nasals with /o/ is zero. ${ }^{10}$ The figures are too low to draw serious conclusions, for which a much longer wordlist would be needed, but, if taken into account, they should imply that Lavukaleve favors intervocalic /ne/ and /nu/ more than $/ \mathrm{je} /$ and $/ \mathrm{nu} /$, which would make much more probable a change from $/ \mathrm{n} /$ to $/ \mathrm{n} /$ than its opposite. Yet, even not taking into account the frequencies of combinations between nasals and vowels because of the low figures, my proposal for a reconstructed Lavukaleve 2 SG pronoun is * yo, due to the other reasons discussed above.

In La.4, a plural marker is identified: $-\beta a$ in demonstratives and the punctual imperative suffix, $\beta$ - as object prefix, $-\beta$ as agreement suffix and present subject agreement, and $-b a$ as durative imperative suffix. The present subject agreement and imperative suffixes refer to the 2nd person, while the other morphemes refer to the 3rd person. However, it can be clearly seen in table 9 that these are the only plural forms in all these morphemes, given that some lack 2 nd person and some lack 3rd person. Therefore, these forms seem to derive from a common plural marker. The existence of $-b a$ points to it as the original form, given that a lenition $/ \mathrm{b} />/ \beta /$ is much more common than the rarer change $/ \beta />/ b /$. 10. The figures for the four Central Solomons languages are shown in detail in table 15 (in 5.2). 
The original vowel should be /a/, not only because of its higher frequency, but also because /o/ in $\beta o-$, as is shown in La.8, seems to be a marker of feminine origin used for the three genders when there is no gender distinction. Accordingly, I posit a reconstructed plural marker*-ba.

The dual marker le/lo/la/l identified in La.5 derives clearly from the numeral 'two': 'lelaol, 'lelemal, 'lelagel, and 'lemal for feminine, masculine, neuter, and counting, respectively (Terrill 2003:53). All forms for 'two' start with $l e-$, and this is also the most used form in table 9 . Therefore, the reconstructed dual marker must be *le.

The form me/ $m$ shown in La.6 indicating 1NSG.INC and 2NSG always occurs as me except in 2DU 'imil and 2PL 'imi. It is shown in La.3 that $i$ - appears in all 2nd person pronouns, which clearly points to it as a 2 nd person marker. Therefore, there must have been a change *'imel $>$ 'imil and *'ime $>$ 'imi, in which /e/ was raised under the influence of the initial $/ \mathrm{i} /$.

Following from all of this, the proposed GPN morphemes for Pre-Lavukaleve are shown in table 10. There are no 3rd person pronouns because Lavukaleve uses demonstratives instead. The forms without asterisks are current forms for which no reconstruction has been performed because all their occurrences are identical.

\section{TABLE 10. RECONSTRUCTED PRE-LAVUKALEVE GPN MORPHEMES}

\begin{tabular}{|c|c|c|c|c|c|}
\hline $1 \mathrm{SG} *$ yai & $1 \mathrm{INC} / 2 \mathrm{NSG}$ & *me & DU & *le & 2nd person \\
\hline 2SG * ${ }^{2}$ & 1NSG.EXC & e & PL & *ba & \\
\hline
\end{tabular}

2.4 BILUA. For Bilua, I reproduce as table 11 the table shown in Obata (2003:49), given that it does the same kind of thing that I have been doing for the other languages: it puts together the different GPN morphemes. These morphemes are called "definite pronouns" by Obata. I have not found other morphemes that may add anything interesting to what already appears in Obata's table.

2.4.1 Relations among GPN morphemes. The relations identified among the different morphemes are as follows:

Bi.1. All 1st person pronouns except 1DU.EXC have a similar form 'aya/'ani-. The 1SG proclitic also has the related form $a=$.

Bi.2. Most morphemes with the same combination of gender, person, and number show similar forms: all 2SG morphemes have the form $\eta o / \eta /=\eta a$; the 3SG.M distal demonstrative, proclitic, and object clitic have the form $\beta o / o=/ \beta(o=$ can be considered a development of $\beta$ o through elision of $\beta$ ); all 3SG.F morphemes apart from the enclitic have the form $k o / k$; all dual morphemes have the form $g e / g / k$; the 3DU pronouns and enclitic start with no-; all 1PL.EXC morphemes have the form $\eta e$; and all 1PL.INC and 2PL morphemes have the form $m e$.

Bi.3. All 1st and 2nd person object clitics except $2 \mathrm{SG}$ have the form $l$.

Bi.4. Most enclitic morphemes have the form $l a$.

Bi.5. All proximate demonstratives end with $-i$.

2.4.2 Internal reconstruction. The relation Bi.1 concerns the development of 'ana and 'ani- from a common preform, while $a=$, if actually related to the other two mor- 
TABLE 11. BILUA GPN MORPHEMES ${ }^{\dagger}$

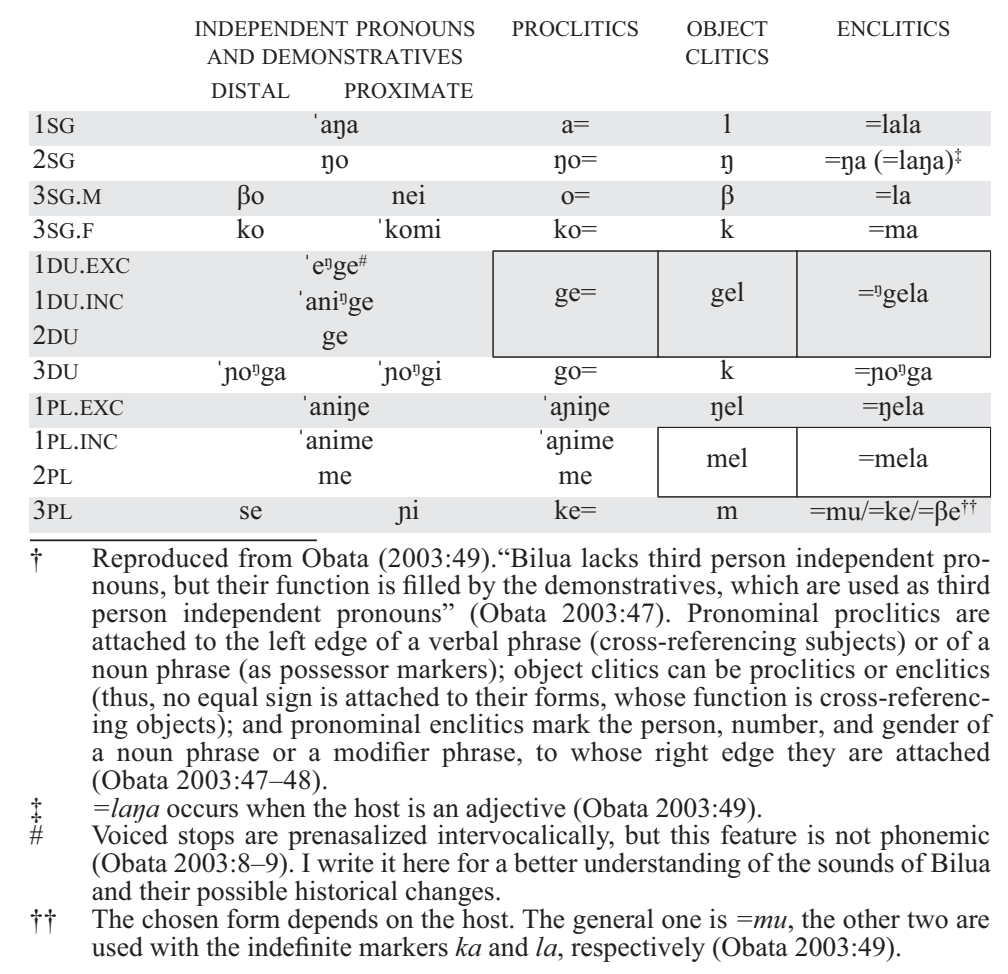

phemes, is clearly formed by a loss of the second syllable due to its proclitic position. The main clue to finding out the preform is given in the phonetic environment of 'ani- (the last syllables of the pronouns 'anilge, 'anine, and 'anime). If the preform were *'ana, there would be a reason for hypothetical preforms such as *'ajage, *'anane, and *'aname to become *'anege, *'ayene, and *'ayeme, respectively, through assimilation to the last syllable, but there would be hardly any reason to continue raising the vowel to $/ \mathrm{i}$ /, as in *'ani-. If the preform were *' ani, it is possible that its independent occurrence in 1SG might lead to the present form 'aya through assimilation of the second vowel to the first and a velarization of the palatal nasal favored by the central-back position of $/ \mathrm{a} /$ instead of the high frontal position of /i/. Thus, the path of evolution would have been *'ani > *'ane $>*^{\prime}$ ana $>$ 'ana.

Nonetheless, another possibility also appears quite feasible: that both 'ana and aniderive from a preform *'anai. The path *'anai $>$ 'ana (through loss of /i/), and *'anai $>$ *'ani- $>$ 'ani- (through the diphthong collapsing as /i/ due to its medial and unstressed position and an alveolarization of the nasal through contact with /i/) is also a reasonable possibility. Therefore, I will posit two possible 1SG pronouns for Pre-Bilua: *'ani and *'anai. Although this is an internal reconstruction in which only the treated language should be taken into account, it is impossible to avoid thinking of the Savosavo 1SG pronoun a 'ni, identical to Bilua 'ani-. ${ }^{11}$ 
The morphemes described in Bi.2 form groups with the same GPN values, and the difference in each group is mainly the loss of a vowel in some clitics. Obviously, the reconstructed form must be with the vowel, given that it is always lost due to its clitic position.

The group indicating dual number $g e / g / k$ deserves special mention. The $3 \mathrm{DU}$ form $k$ is an object clitic, which can be proclitic or enclitic: it is proclitic with only four verbs, and enclitic with all others (Obata 2003: 48). Therefore, the object clitics are enclitics in most cases, and their final position makes a development $/ \mathrm{g} />/ \mathrm{k} /$ more likely than the opposite. Accordingly, I posit * ge as the preform for the morpheme indicating dual number. This form seems to be related to the Bilua numeral 'two', 'omiga or 'muga.

The reconstructed Bilua preforms are shown in table 12. Forms without an asterisk are the current ones and show no variation in the different morphemes.

\section{TABLE 12. RECONSTRUCTION OF PRE-BILUA PRONOUNS}

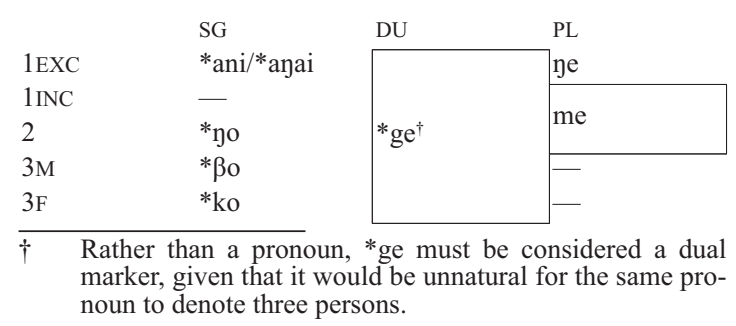

3. COMPARISON. In the preceding sections, the relations among the GPN morphemes in each language have been analyzed, and on this basis an internal reconstruction of the relevant morphemes of each language has been proposed. In this section, I will describe similarities between the different languages, not only among the reconstructed forms, but also among morphemes in which specific GPN values have been identified. In this way, it will be shown that the similarity is based not only on the hypothetical internal reconstruction, but also on the actual current forms.

I reproduce here (as tables 13-16) the tables of reconstructed pronouns, so that similarities can be clearly observed. The Touo 1SG and 2SG pronouns, which do not appear in table 8 , have been added in the list below. Current forms are not asterisked.

There are some similarities among the four languages, some among three of them, and some only between two languages. I will begin with the simplest relation, similarities between only two languages, and will end with the more complex relations among the four languages, which will serve as the discussion focus of sections 4,5 , and 6 .

3.1 SIMILARITIES BETWEEN ONLY TWO LANGUAGES. There are two of these:

(1) Savosavo 1DU.EXC *a-ue, in which $a$ - is an exclusive marker and *-ue a dual marker, is almost identical to the Bilua dual marker *ge. These reconstructed pronouns are based on Savosavo $m e / u$ (Sa.3) and Bilua $g e / g / k$ (Bi.2). The coincidence

11. After personal discussion with Obata, it seems that Bilua has no phonological contrast between [ni] and [ni]. Thus, Bilua /ni/ must be considered identical to both Savosavo /ni/ and /ni/. 
TABLE 13. SAVOSAVO (= TABLE 4$)$

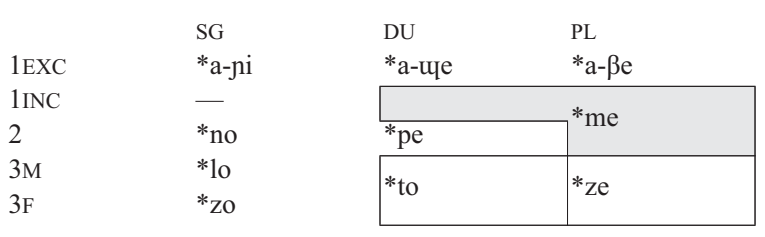

TABLE 14. TOUO (= TABLE 8 PLUS 1SG AND 2SG)

$\begin{array}{llllllll}\text { 1SG } & \text { ẹi } & \text { DU.F } & * \text {-me (reduplication) } & \text { TR.F } & \text { nu } & \text { 3SG.M } & \text { *zo } \\ \text { 2SG } & \text { noe } & \text { DU } & * \text { Ie } & \text { PL.ANI } & * \text { mo } & \text { 3SG.N1 } & \text { na } \\ \text { 1INC/2NSG } & * \text { me } & \text { TR.M } & \text { no } & \text { PL.INAN no } & \text { 3SG.N2 } & \text { yo }\end{array}$

TABLE 15. LAVUKALEVE (= TABLE 10)

$1 \mathrm{SG} *$ yai

2SG *yo
$1 \mathrm{INC} / 2 \mathrm{NSG} \quad * \mathrm{me}$
DU *le
1NSG.EXC e
$\mathrm{PL} \quad *$ ba
2nd person i-

TABLE 16. BILUA (= TABLE 12)

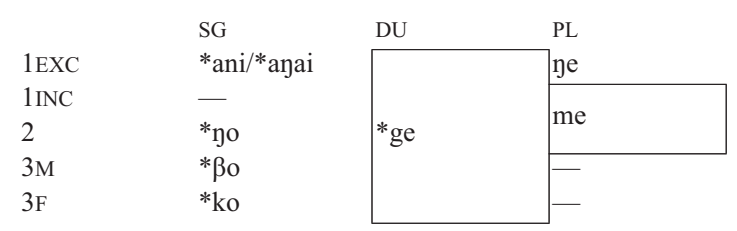

exists as a dual marker, although in Savosavo it only occurs in the first person. This velar dual marker seems to be related to the Bilua numeral 'two' ( $o$ 'muga or 'muga).

(2) The Lavukaleve plural *ba is similar to Savosavo *- $\beta$ e in 1PL.EXC *a- $\beta$ e. These reconstructions are based on Lavukaleve $-\beta a / \beta /-b a$ (La.4) and Savosavo $-\beta e / \beta$ (Sa.3). Savosavo *a- $\beta$ e is formed by 1EXC $a$ - plus PL *- $\beta$ e, so that Lavukaleve *ba and Savosavo *-ße both express plural number.

Therefore, the identified relations are: (1) a relation between Savosavo and Bilua in the dual marker, and (2) a relation between Savosavo and Lavukaleve in the plural marker.

3.2 SIMILARITIES AMONG THREE LANGUAGES. Again, there are two of these:

(1) Savosavo 3SG.F *ko, based on ko/mo/k/m (Sa.3), is identical to Bilua 3SG.F *ko, based on $k o / k(B i .2)$. These forms resemble Lavukaleve 3SG.F and 3DU.F $-h$ - in distal and unspecified demonstratives (La.4), given that a development from $/ \mathrm{k} /$ to $/ \mathrm{h} /$ is well known in other language families (for example, from Proto-Indo-European to Proto-Germanic).

(2) Touo dual marker *Ie, based on de/.t- (To.4), is almost identical to Lavukaleve dual marker *le, based on le/lo/la/l (La.5), and they can be considered totally identical because $/ \mathrm{J} /$ and $/ 1 /$ are the only lateral phonemes in Touo (Dunn and Terrill 2003:180) and Lavukaleve (Terrill 2003:16), respectively. In Savosavo, a lateral dual marker 
also occurs with $=l o$ as number enclitic, which has only a dual $(=l o)$ and a plural $(=u a)$ form and whose function is to mark number on noun phrases when the head of the noun phrase does not inherently mark number (Wegener 2012:127). Therefore, the relation between Touo and Lavukaleve seems quite clear, while Savosavo seems to show a reflex of a dual marker almost lost in this language.

There are, thus, two threefold similarities: one among Savosavo, Bilua, and Lavukaleve, and another among Touo, Lavukaleve, and Savosavo. In (1), the relation is very clear between Savosavo and Bilua, but not so clear in Lavukaleve; in (2), there is a clear relation between Touo and Lavukaleve, but this is not so clear in Savosavo.

3.3 SIMILARITIES AMONG ALL FOUR LANGUAGES. The similarities among all four languages are the most important, given that a high number of possible pronominal cognates ordered in a similar paradigm might be conclusive proof of their genetic relation. The fact that a similar form occurs in four different languages makes it more implausible that the resemblance may be due to chance or borrowing, and even much more implausible if the resemblances are arranged in a similar paradigm. The resemblances identified are as follows:

(1) The 1SG forms in the four languages are clearly related: Savosavo *a-ji, Touo ei, Lavukaleve *yai, and Bilua *ani/*anai. The reconstructions are based on relations Sa.1, La.1, and Bi.1. As was mentioned in 2.4.2, what is remarkable here is the coincidence of the Bilua prefixed form 'ani-, present in 1DU.INC and 1PL, with the Savosavo pronoun $a^{\prime}$ hi. This coincidence will be studied in detail in section 5.1.

(2) The forms of the 2 SG morphemes are practically identical in the four languages: *no in Savosavo, noe in Touo, and *yo in Lavukaleve and Bilua. The reconstructions are based on relations Sa.3, La.2, and Bi.2. The differences concern the place of articulation of the nasal consonant: alveolar in Savosavo and Touo, and velar in Lavukaleve and Bilua.

(3) Another similarity among the four languages exists in the forms used to express an exclusive meaning: $a$ - in Savosavo, $e$ - in Touo, $e$ in Lavukaleve, and $e$ - in the Bilua 1DU.EXC ' $e$ ge, where - ${ }^{\prime} g e$ has been identified as a dual marker (relation Bi.2). This similarity does not concern reconstructions, but current pronouns in the four languages. The exclusive function is identified in relations Sa.5, To.1, and La.7.

(4) The form *me has the same form and meaning in all four languages: it expresses 1PL.INC and 2PL. It also expresses 1DU.INC and 2DU in Touo and Lavukaleve, and 1DU.INC in Savosavo. In other words, *me expresses 1NSG.INC and 2NSG in the four languages, with the exception of Savosavo 2DU and Bilua 1DU.INC and 2DU. The reconstructions are based on relations Sa.3, Sa.4, To.6, To.8, La.6, and Bi.2.

This common form shows a syncretism between 1INC and 2NSG in the four languages. Syncretisms in clusivity are examined by Cysouw (2005), who argues that the typical inclusion of inclusive and exclusive categories in the first person is artificial, given that "an inclusive refers to both first and second person, so it could just as well be analyzed as a kind of second person. An exclusive refers to both first and third person" (Cysouw 2005:73). Indeed, inclusive is treated as a second person in the Central Solomon languages, given that the inclusive either has the same 
form used for the second person or is formed with the same root as the second person. Cysouw (2005:81) studies the different kinds of syncretism in clusivity and, in the section devoted to the syncretism between inclusive and second person, he says that "the notoriously recurring example in the literature of a syncretism between inclusive and second person is the Algonquian family," and that "besides the Algonquian languages, it turns out to be rather difficult to find good examples of a syncretism between inclusive and second person." Cysouw (2005:82) mentions Lavukaleve, and says that "this syncretism is probably the result of a recent merger. The closely related language Savosavo differentiates between an inclusive mai and a second-person plural me (Todd 1975:813)." In his appendix, Cysouw (2005:103) lists the different types of syncretisms in clusivity and the languages that show them, indicating whether the syncretism exists in the independent pronouns or in the inflectional marking. He classifies the Lavukaleve syncretism as inflectional. Wegener's Savosavo grammar (2012) was not published when Cysouw wrote this book chapter, so that his source for Savosavo is Todd (1975). Todd's list of pronominal subject and possessive affixes (her terminology) (1975:814-15) clearly shows the syncretism in Savosavo, so it seems that Cysouw missed this list, otherwise he would have recognized the syncretism. On the other hand, Todd's pronoun list (1975:813) does not show the Savosavo 1SG form ai, which only appears in Wegener's grammar. In this way, it would have been very difficult for Cysouw to notice mai as a sum of $m e+a i$ with Todd's data.

In order to better identify the nature of the inclusive category in these languages, in what follows I will change the terminology of 1INC and will call it only $I N C$. If speakers of Central Solomons languages had developed a theory of grammar independently, as speakers of Indo-European languages did, probably they would have called the inclusive forms second person inclusive. Speakers of Indo-European languages created the term inclusive to indicate that the addressee is included, but the relations of the different GPN morphemes show that speakers of Central Solomons languages use the inclusive forms to express that the speaker is included in the reference to the 2 nd person. The reason for changing the terminology is to prevent the reader from being influenced by repeated references to the 1st person when referring to inclusive, which can make more difficult the association of inclusive with the 2 nd person.

The four similarities shown above concern first and second person pronouns, which are known to be among the most stable word classes. Therefore, these similarities are a good argument in favor of the genetic relationship of the four languages and are the basis for a reconstruction of the pronouns of the protolanguage, which will be performed in section 5. But before embarking on this task and providing arguments for the existence of a genetic relationship, it is necessary to check if some of the forms studied show any relation with neighboring Oceanic languages in order to discard similarities due to borrowing.

3.4 COMPARISON WITH THE OCEANIC LANGUAGES ROVIANA AND GELA. The Central Solomons languages are surrounded by Oceanic languages, with which they have been in contact during the last 3,500 years, although Terrill 
(2011:313) says that there has been "relatively little linguistic material" borrowed in either direction. In tables 17 and 18, the paradigms of some GPN morphemes in the Oceanic languages Roviana and Gela, respectively, are shown. Roviana is geographically very close to Touo, and Gela is close to Savosavo (see exact location in map 1). With these tables, the existence of a possible similarity with the GPN forms studied in the preceding sections can be checked.

No principled resemblance with the Central Solomons languages is evident. The only similarities that may be posited are the formation of the Gela dual with ro- in relation with the lateral dual in Touo, Lavukaleve, and, in a limited way, Savosavo (see 3.2), and the $2 \mathrm{SG}$ yo- in both Roviana and Gela, which is similar to the reconstructed 2SG pronoun in Lavukaleve and Bilua *no (same vowel, and a velar consonant). However, yo- derives from Proto-Oceanic *[i]ko[e] (Lynch, Ross, and Crowley 2002:67-69), and a relation of Bilua and Lavukaleve *no to the nasal-initial 2SG pronominal forms of Savosavo and Touo appears more plausible. The Gela dual pronouns derive from Proto-Oceanic *rua 'two' (Greenhill, Blust, and Gray 2008). In this instance, a relation between *rua and the lateral dual in Touo, Lavukaleve, and Savosavo cannot be discarded.

\section{TABLE 17. SOME GPN MORPHEMES IN ROVIANA ${ }^{\dagger}$}

\begin{tabular}{|c|c|c|c|c|c|}
\hline & ABSOLUTIVE & $\begin{array}{l}\text { ERGATIVE/ } \\
\text { NEUTRAL }\end{array}$ & FOCAL & $\begin{array}{l}\text { PREPOSED } \\
\text { POSSESSOR }\end{array}$ & $\begin{array}{l}\text { POSTPOSED } \\
\text { POSSESSOR }\end{array}$ \\
\hline $1 \mathrm{SG}$ & rau & rau & 'arau & 'gua & 'taga \\
\hline $2 \mathrm{SG}$ & yoi & yoi & 'ayoi & 'mua & 'tamu \\
\hline $3 \mathrm{SG}$ & 'asa & $\mathrm{sa}$ & 'asa & 'nana & 'tani \\
\hline 1PL.INC & 'yita & 'yita & 'ita & 'nada & 'tani \\
\hline 1PL.EXC & yami & 'yami & 'yami & 'mami & 'tani, 'tami \\
\hline $2 \mathrm{PL}$ & 'yamu & 'yamu & 'yamu & mia & 'tani, 'tamu \\
\hline 3PL & 'sari(ni) & ri(ni) & 'a'rini & dia & 'tadi \\
\hline
\end{tabular}

$\uparrow \quad$ Adapted from Corston-Oliver (2002).

\section{TABLE 18. SOME GPN MORPHEMES IN GELA ${ }^{\dagger}$}

\begin{tabular}{|c|c|c|c|c|c|c|}
\hline & INDEPENDENT & POSSESSOR & OBJECT & PAST & PRESENT & FUTURE \\
\hline $1 \mathrm{SG}$ & (i)' nau & $-g u$ & $-\mathrm{u}$ & $\mathrm{u}$ & tu & $\mathrm{ku}$ \\
\hline $2 \mathrm{SG}$ & (i)' yoe & $-m u$ & - - о & o & to & ko \\
\hline $3 \mathrm{SG}$ & 'gaja & - na & $-\mathrm{a}$ & $\mathrm{e}$ & te & ke \\
\hline 1DU.INC & ro'yita & & & & & \\
\hline 1DU.EXC & ro'yami & & & & & \\
\hline 2DU & ro'yamu & & & & & \\
\hline $3 \mathrm{DU}$ & ro'gaira & & & & & \\
\hline 1TR.INC & tolu' yita & & & & & \\
\hline 1TR.EXC & tolu'yami & & & & & \\
\hline $2 \mathrm{TR}$ & tolu' yamu & & & & & \\
\hline $3 \mathrm{TR}$ & tolu'gaira & & & & & \\
\hline 1PL.INC & (i) 'yita & - da & -yita & ta & ta & $\mathrm{ka}$ \\
\hline 1PL.EXC & (i)' yami & -mami & -yami & tai & tai & kai \\
\hline $2 \mathrm{PL}$ & (i)' yamu & - miu & -уamu & tau & tau & kau \\
\hline $3 \mathrm{PL}$ & 'gaira & -dira & $-\mathrm{ra}$ & (ta)ra & 'tara & kara \\
\hline
\end{tabular}


Although these phonological similarities may be posited, the major difference between the Oceanic languages Roviana and Gela and the Central Solomons languages lies in the fact that the tables of GPN morphemes in Roviana and Gela show a very different pattern from those of the Central Solomons languages. Roviana has only singular and plural numbers, and the dual and trial in Gela are clearly formed with the addition of roand tolu- to the corresponding plural forms - cf. Gela rua 'two' and tolu 'three' (Crowley 2002:528), identical to the number prefixes if we consider $r o$ - an abbreviated form of rua. This number distribution is very different from that studied in the preceding sections in the Central Solomons languages, in which dual and trial are not formed in such a straightforward way (with a prefix common for all pronouns with the same number, which has the same form as the corresponding numeral). Moreover, the 2PL form ' $\mathrm{y} a \mathrm{mu}$ in both Oceanic languages is more similar to their exclusive 'jami than to their inclusive 'yita, while we have seen that the 2PL morphemes of the Central Solomons languages are related to their inclusive morphemes. In this regard, Cysouw (2005:86) says that "a syncretism between exclusive and second-person plural is also found in various Western Oceanic (also Austronesian) languages," and Lynch, Ross, and Crowley (2002) classify Roviana as a Western Oceanic language. However, it seems that this syncretism or similarity goes back to Proto-Oceanic, whose forms are 1PL.INC *kita, 1 PL.EXC *kami/ *kamami, and 2PL *kamiu (Greenhill, Blust, and Grey 2008). This implies that not only Roviana and Gela, but every Oceanic language that has had some kind of contact with the Central Solomon languages probably had this syncretism between 1PL.EXC and 2PL.

Thus, the only relation that might be plausible between the Central Solomons languages on the one hand and Roviana and Gela on the other in their GPN morphemes is the common occurrence of a liquid in the dual number, which might be related to or derivable from Proto-Oceanic *rua 'two'.

\section{ARGUMENTS FOR THE EXISTENCE OF A GENETIC RELATION.}

In this section, I will show that I consider the four languages to be genetically related, since there are too many similarities to be due to chance or borrowing.

Ross describes the problem of the Central Solomons languages very clearly:

In a sense, our findings with regard to the Solomons family have come full circle. Wurm (1975) classified them as a single group, apparently on the basis of lexicostatistics (his grounds are not made explicit). Todd showed, however, that it was very difficult to recognise cognates across the four languages or even between pairs of languages, but recognised resemblances among the pronoun sets. Scholars working on these languages usually comment on the striking differences among them rather than on any family resemblance (Evelyn Todd, Kazuko Obata, Angela Terrill, pers. comm.). Yet when the pronoun forms are tabulated and reconstructions are made, their cognacy is fairly obvious." (Ross 2001:311)

The similarity of some pronouns is indeed noticeable at first sight. The step forward that this article tries to take consists in the recognition of similarities that are not noticeable at first sight and that have not been recognized in the previous literature. 
1st and 2nd person pronouns are known to be especially stable words. It is, therefore, no surprise that the similarities found among the four languages in section 3.3 concern only 1st and 2nd person pronouns, while similarities found only among two or three languages concern other GPN morphemes. The similarity in the 2SG pronoun, described in (2) in 3.3, is clearly noticeable due to the almost identical forms; the similarity in the 1SG pronoun, described in (1) in the same section, although not so clear as the 2SG pronoun, is also noticeable at first sight; but similarities (3) and (4) regarding the expression of clusivity and 2PL forms are not noticeable without a detailed analysis.

The common form Sa. $a$-, To. e-, La. $e$, and Bi. $e$ - has been recognized through the analysis and comparison of the different parts of the GPN morphemes. This form is identical in three languages - with the slight variation of the breathy voice in Touo - and is represented by a close vowel in Savosavo. There is also the fact that the morpheme is expressed by a single vowel in the four languages. The similarity based only on a single vowel might suggest a high possibility of being due to chance, but this impression is misleading. These languages all have five-vowel systems, except for Touo, which has six (Wegener 2012:19-20; Dunn and Terrill 2003:178; Terrill 2003:16; Obata 2003:10). Thus, given a language with $e$ expressing one meaning, the probability of the same vowel appearing with the same meaning in another language is $1 / 5$, that is 0.2 . If we add a third language with six vowels, the probability of the same vowel appearing in the three languages is $1 / 5 \times 1 / 6$, that is 0.0333 . If we consider Savosavo and the probability of the same or a close vowel (that is $/ \mathrm{a} /, / \mathrm{e} /$, or $/ \mathrm{i}$ ) appearing, then the probability is $1 / 5 \times 1 / 6 \times 3 / 5$, that is 0.02 , or 2 percent. But we should multiply this figure by the low probability of a language having a pronominal element with no consonant. In this case, the calculation turns out to be quite difficult to formulate, but, knowing that pronouns tend to have at least one consonant, the 2 percent of probabilities multiplied by the probability of all four languages having no consonant in a pronominal form would result in a very low likelihood that this similarity is due to chance.

But in my view, the most important finding of the analyses carried out above is the syncretism between inclusive and 2NSG in a morpheme that has exactly the same form in the four languages: *me. This is indeed a reconstructed form that, however well founded, is bound to be hypothetical. Nonetheless, the forms on which the reconstructions are based offer little doubt: Savosavo INC pronoun mai (2PL $m e+1 \mathrm{SG} a$ ) and subject enclitic $=m e$, and 2PL $m e$; Touo trial and plural forms of inclusive and 2nd person $m e-;$ Lavukaleve DU.INC $m e l$ (where $-l$ is a dual marker), PL.INC me, 2DU imil (where $i$ - is common for 2nd person pronouns), and 2PL imi; and Bilua PL.INC -me and 2PL $m e$. The question that arises here is whether it is possible that this striking similarity might be due to something other than common origin. The two factors that can explain a coincidence in form and meaning different from a genetic relation are chance and borrowing.

In 3.3, I cited Cysouw (2005:81) as saying that "it turns out to be rather difficult to find good examples of a syncretism between inclusive and second person." If this kind of syncretism in clusivity is rather rare and four languages spoken in the same area share it and express it with the same form, I think that the probability of chance does not deserve even to be calculated, if such a calculation might be devised with reasonable accuracy. Ross (2005:52-53) mentions two language families with a 1st and 2nd person pronomi- 
nal paradigm similar to the one he posits for Proto-Trans-New Guinea: Algonquian and Chadic; and he attributes the similarity to chance because they are spoken in very distant areas, in contrast with the Trans-New Guinea languages, which are spoken contiguously. I do not know if there is any other language in the world that shows a syncretism between inclusive and 2 nd person represented by the form me, but I would not be surprised if such a language did not exist outside the Solomon Islands.

Regarding borrowing, the GPN morphemes tables of Roviana and Gela in 3.4 do not show this kind of syncretism and, as I pointed out in the same section, the tendency in the Oceanic languages of the area seems to be to a syncretism between 1EXC and 2nd person. However, the possibility of the Central Solomons languages borrowing from each other deserves some discussion. Leaving aside the debate on the rareness of pronoun borrowing, there are some factors to consider regarding these languages. First, the languages are spoken in the same area, but are not contiguous. Second, as Ross's quote above states, it is very difficult to recognize cognates. If one language had borrowed pronouns from another, it would be reasonable to expect that a considerable amount of (other) vocabulary has also been borrowed, which does not seem to be the case. Regarding the matter of the geographic location, we would need to think of certain scenarios that favored borrowing among the four languages. One scenario would be a high maritime mobility that allowed a frequent interaction among speakers of the four languages; another would be that the speakers of these languages once lived in contiguous areas, or many languages were spoken in a contiguous area where some borrowings were diffused throughout the whole area, of which only the four languages treated here have survived. The latter scenario seems to me more plausible than that of the maritime mobility, which could explain some borrowings, but could hardly explain how this syncretism with its corresponding pronouns was borrowed across the four languages. The scenario of the speakers of the four languages living in a contiguous area in the remote past might explain the borrowing of the pronouns and the syncretism, but this is also the scenario that explains genetic relationship, that is, that speakers of one language living in the same area migrated and this language diversified into several daughter languages. This hypothetical scenario would have existed most probably in a time prior to the arrival of speakers of Oceanic languages, which may have caused migrations of which we have no knowledge.

In this way, the borrowing hypothesis seems to imply a scenario similar to that of the common origin hypothesis. We might imagine speakers of the four languages living in the same area 4,000 years ago and becoming highly influenced by each other, thus borrowing a large amount of vocabulary, including pronouns. Later, these languages would have evolved separately until the present situation, in which pronouns would be the only remnant of the massive borrowing. The same can be said of the common origin hypothesis, in which pronouns would be the only remnant of the common mother language. The borrowing hypothesis implies that the speakers of the four languages settled in contiguous areas and spoke unrelated languages. This leads us to the question of the likelihood of pronoun borrowing.

Ross (2005:53-58) offers a good discussion on the likelihood of pronoun borrowing. His main conclusion is that pronoun borrowing "occurs in circumstances where, for one or other reason, speakers perceive the pronoun system as in need of repair or augmenta- 
tion" (Ross 2005:54), but "neither phonological attrition nor augmentation of an open system leads naturally to a situation where a complete paradigm is replaced by borrowing, and full paradigmatic replacement occurs under quite different kinds of circumstances" (Ross 2005:57). As examples of this full paradigmatic replacement, Ross (2005:57-58) cites "Copper Island Aleut, which uses Russian finite verbs in an otherwise largely Aleut matrix," and Meglenite Rumanian, in which "Bulgarian person/number suffixes replaced their Rumanian equivalents on the Meglenite verb"; and finally says that "even in the rare cases where a paradigm is replaced, we do not find that all pronominal paradigms have been replaced."

This discussion on pronoun borrowing started with the possibility of *me and the syncretism it entails being borrowed among the Central Solomons languages, but at this point the discussion leads to the possibility of a whole paradigm being borrowed. In this section, I have talked about two of the four similarities among the four languages shown in 3.3, namely a-/e-/e as an exclusive morpheme and *me representing the syncretism between inclusive and 2nd person. Exclusive and inclusive are grammatical categories not found in all languages: they are present in only a minority of languages (68 out of a sample of 200 in Cysouw 2013). The other two similar forms in the Central Solomons languages are 1SG *ani/ei/*nai/*ani/*anai and 2SG *no/noe/*no. With this we have a whole paradigm of 1st and 2nd person with four very similar or identical forms in the four languages together with an identical syncretism in clusivity. This is the main argument that is provided here in favor of the genetic relatedness of these languages. Todd (1975:813-14) recognizes some of the similarities shown here, namely in 1SG, 2SG, and 2PL, and she adds that "inclusive first person plurals are somewhat similar to one another and also resemble the second person plurals with the characteristic consonant $m$," and that "Savosavo and Bilua first person exclusive forms are similar in overall structure." She notes the resemblance between inclusive and 2nd person and the similar exclusive forms, but does not analyze these resemblances in detail. This detailed analysis and the recognition of its importance is the main contribution of this article to the literature on the subject.

\section{RECONSTRUCTION OF SOME PROTO-CENTRAL SOLOMONS}

PRONOUNS. In this section, I carry out the reconstruction of 1SG, 2SG, 2PL, inclusive, and exclusive pronouns in Proto-Central Solomons. The reconstructions are based on the internal reconstructions of each language, but the current forms used for the internal reconstructions are also shown so as to provide the reader with a clearer picture of all the proposed changes.

5.1 FIRST PERSON SINGULAR. The internally reconstructed 1SG pronouns are Sa. *a-ni (based on a'ni/ai/n-/-ni/=ne), To. ei (current form), La. *yai (based on yai/ $\eta a-)$, and Bi. *ani/*anai (based on a a a/ani-). The choice of one of the two preforms proposed for Bilua is crucial for positing a Proto-Central Solomons reconstruction.

As was pointed out in 2.4.2 and 3.3, the striking fact is the identical form of the Savosavo 1SG pronoun $a^{\prime} n i$ and the Bilua 1st person prefix ani-, present in DU.INC, PL.INC, and 1PL.EXC. These forms suggest that Bilua's 1SG pronoun was once *ani and evolved to the present 'ana, while it did not change where it was prefixed to other forms 
(current 'anige, 'anine, 'anime). If we choose *ani as the Pre-Bilua 1SG pronoun, the reconstruction for Proto-Central Solomons should also be *ani. This hypothesis would imply a change in Touo *ani $>*_{\text {ani }}>$ *aji $>*$ ai $>$ *ei $>$ e $i$; and in Lavukaleve, the change to yai should have started by the prothesis of an initial nasal consonant under the influence of $/ \mathrm{n} /$ in *ani in this way: *ani $>*_{\text {yani }}>*_{\text {yani }}>*_{\text {yaji }}>$ yai. In Savosavo, the only change would have been the palatalization of $/ \mathrm{n} /:$ *ani $>$ a $n$ i.

If we chose Pre-Bilua *ayai, the most reasonable reconstruction for Proto-Central Solomons would be the same form: *anai. In this case, we should posit a parallel evolution in Savosavo and Bilua leading to a 'ni and ani-, which should have run *ayai > *aji $>$ ani to arrive to the Bilua prefixed form, plus the palatalization *ani > ani in Savosavo. The Bilua 1SG pronoun would have been formed by the apocope of /i/: *anai > 'aya; and the different evolution toward this pronoun and the prefixed forms ani- would have been caused by their different phonetic environment: an independent word or prefixed to -Ce forms. The choice of *anai as the protoform makes the posited development process in Lavukaleve shorter, caused by an apheresis of the initial vowel in this way: *anai > yai. The evolution path in Touo would have started with a double apheresis: *ayai > *yai $>$ *ai $>*_{\mathrm{ei}}>$ e $i$.

The *ayai hypothesis implies a much shorter set of changes in Lavukaleve and avoids positing a consonant prothesis - a less common change than the apheresis of a vowel. However, it implies an identical independent evolution in Savosavo and Biluain Savosavo as a free pronoun and in Bilua as a prefixed form. In Touo, both hypotheses lead to an intermediate form *ai, and neither seems more feasible than the other. Therefore, the advantage of the *anai hypothesis is that it explains in a simpler way the evolution of the Lavukaleve pronoun, while the *ani hypothesis explains better the coincidence of the current Savosavo a ni and Bilua ani- without having to posit a parallel identical evolution, though in different phonetic environments. I am inclined to consider the *ayai hypothesis more likely, given that the changes it requires in Savosavo and Bilua (*ayai $>$ *ani $>$ ani and *anai $>$ 'aya) are not uncommon, and it requires fewer steps for Lavukaleve. Nonetheless, I will include both forms in the list of proposed Proto-Central Solomons pronouns because the *ani hypothesis also seems to me quite reasonable.

5.2 SECOND PERSON SINGULAR. The proposed $2 \mathrm{SG}$ reconstructed pronouns are Sa. *no (identical to current pronoun), To. noe (no reconstruction because there is no

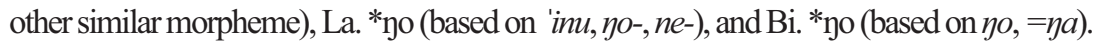
If *no, noe, and *yo derive from a common Proto-Central Solomons form, this form must be posited as *no or *no. First of all, we should consider that the change $/ \mathrm{y} />/ \mathrm{n} /$ is crosslinguistically more common than $/ \mathrm{n} />/ \mathrm{n} /$. This tendency is reflected in the much higher occurrence of $/ \mathrm{n} /$ than $/ \mathrm{y} /$ in pronouns cross-linguistically (Ross 2005:51-52).

Table 19 shows the occurrences of combinations of nonlabial nasals with the five vow$\mathrm{els}^{12}$ of these languages in the wordlists of the Austronesian Basic Vocabulary Database (Greenhill, Blust, and Gray 2008; the source is Tryon and Hackman 1983 for all languages except Savosavo, whose data are from Claudia Wegener). The wordlists have around 200

12. The four languages have the vowels $/ \mathrm{a} /, / \mathrm{e} /, / \mathrm{i} /, / \mathrm{o} /$, and /u/, and Touo also has /o/. However, no combination of a nasal with this vowel has been found in the Touo wordlist. 


\section{TABLE 19. COMBINATIONS OF NONLABIAL NASALS WITH VOWELS IN EACH OF THE FOUR CENTRAL SOLOMONS LANGUAGES ${ }^{\dagger}$}

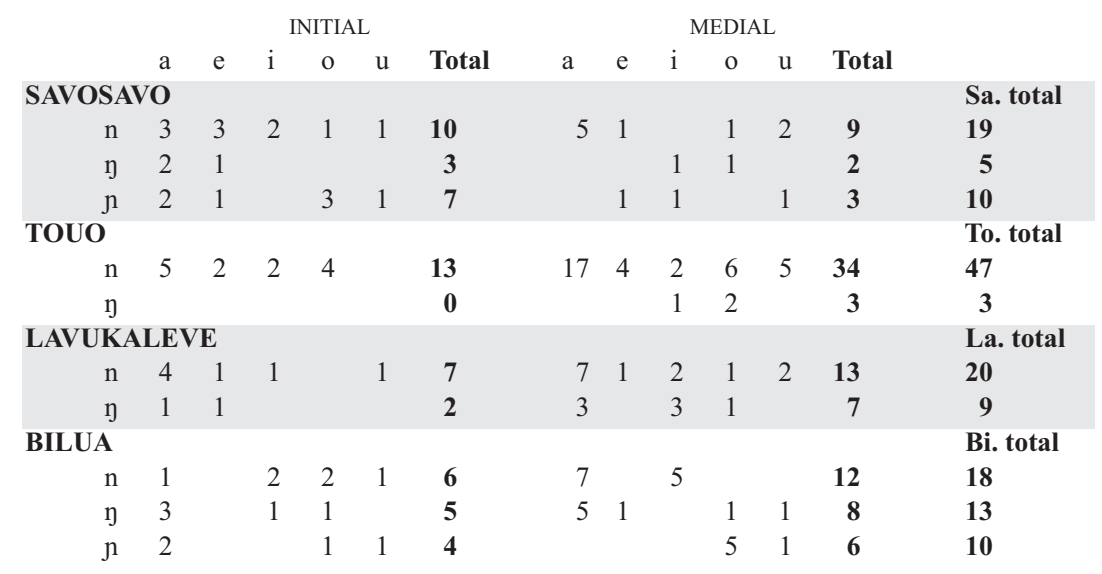

$\dagger \quad$ Figures refer to combinations of nonlabial nasals with vowels in initial and medial syllables in wordlists of around 200 words of basic vocabulary. Data are from Greenhill, Blust, and Gray (2008); the source is Tryon and Hackman (1983) for all languages except Savosavo, whose data are from Claudia Wegener. For example, the 3 in the Savosavo initial $n+a$ indicates that there are three words with /na/ in initial position in Savosavo, and so on.

words. These frequencies might give an idea of the tendency to favor certain nasals in a given language, which might suggest which change (/no/ $>/ \mathrm{no} /$ or $/ \mathrm{no} />/ \mathrm{no} /)$ is more probable. The figures are very low, so it is difficult to draw definitive conclusions; however, there are some tendencies that may be noticed. We can observe a quite higher number of $/ \mathrm{nV} /$ syllables except in Bilua, where, although the number of $/ \mathrm{nV} /$ is higher than $/ \mathrm{nV} /$, the difference is not as great as in the other languages. Although the figures are low, they suggest that a change $/ \mathrm{y} />/ \mathrm{n} /$ is more probable than the reverse. A change $/ \mathrm{n} />/ \mathrm{n} /$, which should have occurred in Lavukaleve and Bilua, would hardly fit the Lavukaleve data, which show a much higher frequency of $/ \mathrm{nV} /$, above all in initial syllables; it would be difficult to explain why such a change should have taken place in Lavukaleve.

Accordingly, I posit the reconstructed 2SG pronoun * ${ }_{\text {no }}$ for Proto-Central Solomons.

5.3 NONSINGULAR PRONOUNS: INCLUSIVE, SECOND PERSON, AND FIRST PERSON EXCLUSIVE. The nonsingular pronouns that are reconstructed here - $\mathrm{INC} / 2 \mathrm{NSG}$ and 1NSG.EXC - pose fewer problems than the singular pronouns treated above due to their practically identical forms in the four languages.

The reconstructed INC/2NSG pronoun *me is identical in the four languages and the current forms are practically identical to the reconstruction, as is shown in similarity 4 in 3.3. Therefore, the reconstruction for Proto-Central Solomons has to be *me.

In similarity 3 in 3.3, I showed a form expressing exclusivity in the four languages. The similarity is not based on internal reconstructions, but on current forms, and they are Sa. $a$-, La. $e(-)$, To. $e$, and Bi. $e$-, the last of these present only in the 1DU.EXC pronoun ' $e$ ge. In Lavukaleve, this form appears in the two exclusive pronouns: dual $e l$ and plural $e$. In Savosavo and Touo, the respective forms $a$ - and $e-$ also exist in the 1SG pronouns 
$a^{\prime} n i$ and ei. This coincidence with the singular pronoun, which also expresses exclusivity because of the very fact of being 1st person and singular, might have been formed in both cases by the force of analogy. In the case of Savosavo, the exclusive pronouns dual 'ame and plural 'aße would have been formed out of *eue and *eße through an analogy with the 1SG a ji. In Touo, the change *ai > ei, proposed in 5.1, would have been favored by pronouns prefixed with e- in dual, trial, and plural. Accordingly, my proposal for a reconstruction of the 1EXC protopronoun is *e.

5.4 RECONSTRUCTION PROPOSAL. Table 20 summarizes the reconstruction proposed in the preceding sections together with the internal reconstructions of the same pronouns for each language. (Current forms have no asterisks.)

TABLE 20. INTERNAL RECONSTRUCTION OF THE PRONOUNS IN EACH LANGUAGE AND IN PROTO-CENTRAL SOLOMONS

\begin{tabular}{|c|c|c|c|c|}
\hline & $1 \mathrm{SG}$ & $2 \mathrm{SG}$ & $\mathrm{INC} / 2 \mathrm{NSG}$ & $1 \mathrm{EXC}$ \\
\hline Pre-Savosavo & *a-ji & $*$ no & *me & a- \\
\hline Pre-Touo & ẹi & noe & *me & e-- \\
\hline Pre-Lavukaleve & *yai & *yo & $*$ me & e \\
\hline Pre-Bilua & *ani/*anai & *no & me & e- \\
\hline Proto-Central Solomons & *ani/*anai & *no & *me & $* \mathbf{e}$ \\
\hline
\end{tabular}

5.5 ROSS'S RECONSTRUCTION. To my knowledge, the only published reconstruction of the pronouns of the Central Solomons languages is in Ross (2001:316-17). This reconstruction is reproduced in table 21. In this section, Ross's reconstructions are compared with the reconstructions proposed in the previous section.

5.5.1 Differences in methodology and approach. First of all, it is important to consider that Ross did not have access to most of the data that I have used in this article. The grammars of Savosavo (Wegener 2012), Lavukaleve (Terrill 2003), and Bilua (Obata 2003) had not been published at that time. For Touo, I have used the data in Todd (1975), to which Ross had access, but he did not have access to the phonological description of this language in Dunn and Terrill (2003), which I have used. Therefore, I have been able to use much more information than Ross had in 2001.

Another important difference is that Ross (2001) is a book chapter that tries to give an answer to its title: "Is there an East Papuan phylum? Evidence from pronouns." Ross's research question is, therefore, concentrated in a number of languages much higher than the four Central Solomons languages - nineteen languages are included in his reconstructions. This article concentrates exclusively on the four Central Solomons languages, which is obviously an advantage, because these languages can be studied in much more depth, which has allowed me to give a detailed account of the way the reconstruction has been performed. On the contrary, Ross does not explain how he carries out his reconstruction, probably due to the high number of languages studied, which would have demanded a whole book instead of one chapter if such a detailed account had been given.

Another difference is the approach: mine consists in identifying forms that recur in different morphemes bearing some GPN values in common, while Ross reconstructs free and bound pronouns for each full GPN combination. My approach departs from the 
TABLE 21. PROTO-CENTRAL SOLOMONS PRONOUNS (Ross 2001:316-17)

$\begin{array}{llll} & \text { SINGULAR } & \text { DUAL } & \text { TRIAL } \\ 1 \text { EXCLUSIVE } & * \text { ya, a, *-la } & * \text { ge } & *(\mathrm{y}, \mathrm{v}) \mathrm{e} \\ 1 \text { INCLUSIVE } & - & - & * \text { mai } \\ 2 & * \text { yo, nu } & * \text { be } & * \text { me } \\ 3 \text { MASCULINE } & * \text {-la } & * l a(/ \text { lo }) & * \text { m }(\mathrm{a}, \mathrm{u}) \\ 3 \text { FEMININE } & * \text { vo, ko, }{ }^{*} \text {-ma } & & \end{array}$

known fact that languages tend to have a grammaticalization path from free pronouns to clitics to affixes, and, thus, forms with specific GPN values may be identified in different GPN morphemes. Ross (2001:305) recognizes this fact when he says, referring to his 1995 reconstruction of the pronouns of the Trans-New Guinea languages, that "in the majority of families, bound and free forms are obviously cognate with each other, and one can infer that the bound forms are the outcome of the cliticization and affixation of earlier free forms." In his 2001 reconstruction of the pronouns of the different putative East Papuan families, in which the Central Solomons languages are included, he actually adopts an approach similar to mine, because he lists different GPN morphemes and then proposes a reconstruction of one or more free and bound pronouns for each full GPN combination in each language. In this way, we can see that Ross is also identifying forms that recur in several GPN morphemes carrying the same GPN information. The main difference from my approach is that he reconstructs forms for each full GPN combination, while I also try to recognize similar forms that carry only one piece of grammatical information regarding gender, person, or number. That means that Ross reconstructs a full pronoun for 2DU, a bound pronoun for 3SG.M, a full pronoun for 2PL, a full pronoun for 3DU, and so on, while I have also tried to find forms that mark only dual, 2nd person, masculine, or plural.

Ross tries to make a reconstruction for every GPN combination, while I have been more conservative: I have proposed a reconstruction only for the forms that show a clear relation in the four languages. In this respect, we have seen that Lavukaleve and Bilua lack 3rd person pronouns and their role is fulfilled by demonstratives. 1st and 2nd person pronouns are much more stable than 3rd person pronouns, which often derive from demonstratives or determiners - think only of Romance 3rd person pronouns and definite articles, which derive from a Latin demonstrative.

Once all these differences are considered, we can see that Ross's reconstruction is not very different from mine. The differences are examined in the next section.

5.5.2 Comparison between both reconstructions. Ross proposes Proto-Central Solomons 2PL *me, while I propose the same form for INC and 2NSG. Ross's reconstructions for 1PL.INC and 2DU are *mai and *be, respectively.

Regarding *mai, Ross gives the form *me as the 1PL.INC preform for all languages except Pre-Savosavo, for which he gives *mai. In this way, his proposal implies that a form *mai changed to *me in all languages but Pre-Savosavo, in which it remained unchanged. A phonetic change from *mai to *me is easily conceivable, and probably this is the reason that led Ross to propose this change instead of a more complex change from

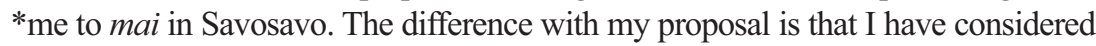
Savosavo 1NSG.INC mai as a union of 2PL me plus 1SG ai. It is important to point out here 
that Ross gives añi as the current Savosavo 1SG pronoun, while I show in table 3 two forms of this pronoun: a 'ni and ai. Probably, Ross did not know about the form ai, on which my proposal is based, given that he did not have access to Wegener's Savosavo grammar (2012).

Ross's Proto-Central Solomons 2DU reconstruction is *be, based on Pre-Savosavo *pe, Pre-Touo *bere, Pre-Lavukaleve *m(e,i)-le, and Pre-Bilua *ge. Pre-Savosavo *pe is identical to my reconstruction. Regarding the other languages, Ross's reconstructions of this pronoun clearly show the difference of his approach from mine, which I have mentioned above. Ross is trying to reconstruct a 2DU pronoun, while I have tried to identify the different parts of the GPN morphemes that carry a specific piece of GPN information. The Savosavo 2DU pronoun does not have similar forms outside the 2DU category, but in the other languages, I have shown that their 2DU morphemes are formed by addition of morphemes carrying some piece of GPN information (section 2). In this way, the Touo 2DU pronoun ${ }^{m}$ bele is formed by ${ }^{m} b e$ (see 2.2.2) plus the dual marker .le; the Lavukaleve 2DU pronoun 'imil can be decomposed as i-mi-l (2nd person-INC/2NSG-dual), and the Bilua 2DU ge is a common form used in all dual GPN morphemes, although it appears alone in 2DU, without more phonetic accompaniment.

Ross proposes * $(\mathrm{y}, \mathrm{v}) \mathrm{e}$ as the Proto-Central Solomons 1PL.EXC form, while I propose *e for 1NSG.EXC. My proposal is, thus, identical to one of the three forms proposed by Ross for 1PL.EXC. The difference lies in the fact that Ross posits different forms for dual and plural. His 1DU.EXC proposal is *ge. In similarity 1 of 3.1, I identify a coincidence between Pre-Savosavo *-ue and Pre-Bilua *ge. The Pre-Savosavo form corresponds to 1DU.EXC, but the Pre-Bilua form is based on a similar form $(\mathrm{ge} / \mathrm{g} / \mathrm{k})$ present in all Bilua dual morphemes. Regarding Touo and Lavukaleve, a lateral dual marker is identified in similarity 2 of 3.2, with Savosavo also having a lateral dual marker only as a number enclitic. Therefore, Ross's *ge does not account for this lateral dual marker. Moreover, it implies an extension from 1DU.EXC to the rest of dual morphemes in Bilua. In 3.4, I note the similarity between the lateral dual marker and Proto-Oceanic *rua 'two', and in 2.4.2 I note the relation of the Savosavo and Bilua velar dual marker with Bilua 'muga 'two'. In this sense, Ross's proposal might be justified if we considered the velar dual marker as the Proto-Central Solomons original, while the lateral dual marker could be an Oceanic borrowing. I do not know if this was Ross's idea. In any case, Ross proposes * ge only for 1DU.EXC and not for other dual forms.

Ross's 2SG reconstructed form for Proto-Central Solomons is *no, *nu. In this case, one of his two proposals is identical to mine: * ${ }^{*}$. His *nu seems to be based on PreLavukaleve *no, *nu, given that this is the only form with $/ \mathrm{u} /$ in the reconstructions of each individual language. This form must be based on the Lavukaleve 2SG pronoun 'inu. I have posited only the form * yo on the grounds given in 2.3.2.

Ross's reconstructed 1SG forms are * ya, *a, *-la, while mine are *ani, *anai. Regarding the free pronouns, Ross gives as reconstructed forms for each language Pre-Savosavo *ñi, Pre-Lavukaleve *na, *a, Pre-Bilua * ${ }^{*}$ a *a, and none for Touo, whose present form is ei. The proposal *na, *a clearly seems to be based on the identical Lavukaleve and Bilua reconstructions, whose present forms are $\eta a i$ and 'ana, respectively. I cannot imagine the reason for the proposal of *a, neither for Lavukaleve and Bilua nor for the Proto-Central 
Solomons reconstruction, considering the existence of nasal consonants in 1SG forms in all languages but Touo. Regarding the form * ${ }^{*}$ a, it is very similar to my proposed *anai. However, Ross does not list the Bilua form ani-, which I have shown in 2.4.1 performing the function of a 1st person marker. The difference in approach again is evident here: Ross considers full GPN morphemes, while I have tried to study how they are built with different parts expressing different GPN values. The consideration of ani- has been crucial for my proposal of both *ani and *anai as the 1SG protopronoun.

Regarding the 3rd person pronouns, I have not proposed a reconstruction for them because I have not found a clear relation among the four languages and I have been conservative in this respect. Moreover, we must take into account that 3rd person pronouns often derive from demonstratives or determiners and are, thus, much less stable than 1st or 2 nd person pronouns. As noted in 1.2, the lack of a high degree of common vocabulary shows that, if the four languages are actually related, the relation must be very ancient. With some millennia of language change, it is difficult for $3 \mathrm{rd}$ person pronouns to conserve clear similarities, so that their reconstruction is always much more speculative than that of 1 st and 2 nd person pronouns.

6. BRANCHING. A conclusive branching proposal would need to be based on shared innovations. This is not possible in this case due to the problem of the lack of cognates mentioned in 1.3. Therefore, any branching proposal is bound to be highly tentative. Nonetheless, there are some facts that provide arguments to support such a tentative branching hypothesis.

6.1 EVOLUTION OF THE INCLUSIVE/SECOND PERSON NONSINGULAR PRONOUN. In my opinion, the most important fact that suggests a branching hypothesis is the different treatment of the syncretism between inclusive and $2 \mathrm{NSG}$, for which I have reconstructed the protoform *me: Savosavo and Bilua form the inclusive by adding GPN morphemes to the 2PL pronoun me, while Touo and Lavukaleve do the reverse: they form the 2PL by adding GPN morphemes to the inclusive pronoun $m e$. In Savosavo, the inclusive mai is formed by adding ai (one of the two forms of the 1SG pronoun) to the 2PL me. In Bilua, the PL.INC pronoun 'anime is formed with the 2PL pronoun me plus the 1st person marker ani-, which is also present in DU.INC 'anige and 1PL.EXC 'anine. In Touo, me alone is present as my reconstructed DU.INC.M prepronoun *me, but if we consider only the current forms, the addition is most clearly seen in the trial pronouns, which are TR.INC.M mens, TR.INC.F menu, 2TR.M me $e^{m}$ bens, and 2TR.F me $e^{m} b e n u$. The 2TR pronouns are formed by adding ${ }^{m} b e$ to the INC.TR forms. In my reconstruction of the Pre-Touo pronouns in table 7, the addition of morphemes to the inclusive pronouns so as to form the 2nd person pronouns can also be observed in dual and plural. Finally, Lavukaleve inclusive pronouns are dual mel and plural me, and 2DU 'imil and 2PL 'imi are formed by adding $i$ - (also present in $2 \mathrm{SG}$ ) to the corresponding inclusive pronouns. I have considered the second /i/ in 'imil and 'imi a phonetic change performed under the influence of the first $/ \mathrm{i}$ ( $($ see 2.3.2).

These different developments suggest an original situation in Proto-Central Solomons in which the syncretism was pure, that is, there was no difference between inclusive and 
2NSG, and some phonetic material was added later so as to avoid misunderstandings. The difference in the addition to one or the other grammatical category may be explained if we propose that Savosavo and Bilua form one subgroup and Touo and Lavukaleve another, and that each subgroup performed a different innovation adding markers to inclusive or 2NSG. A different hypothesis would posit that some of the languages introduced the same innovation separately. However, other developments would also have been possible, as, for example, a total differentiation of inclusive and 2NSG, the emergence of a different syncretism, the conservation of the pure syncretism, or the addition of morphemes to both inclusive and 2NSG. Thus, if the point of departure is a pure syncretism, the possible evolution paths are not only the addition of morphemes either to inclusive or $2 \mathrm{NSG}$, as is the case in the four studied languages.

The syncretism in its purest form does exist in the Savosavo INC and 2PL subject enclitic $=m e$ and the Lavukaleve INC and 2PL subject and object prefix $=m e$. Cysouw $(2005: 103)$ lists only three languages with this kind of syncretism in independent pronouns - Sanuma, Itonama (both Amazonian isolates), and Inanwatan (Trans-New Guinea) - and thirteen with the syncretism in the verbal inflection: six Algonquian languages, Kiowa (Tanoan), Lavukaleve, Tiwi (Tiwian), Acehnese (Austronesian), Diola-Fogny (Atlantic), Kulung (Kiranti), ${ }^{13}$ and again Itonama. As can clearly be seen, this feature does not seem to be frequent and shows no relation with the Melanesian area. Thus, according to Cysouw, Itonama is the language in which this syncretism is clearest. Indeed, the syncretism in Itonama exists in the personal pronouns (INC and 2PL ${ }^{14}$ dihni'tie?ke), in the possessive prefixes (INC and 2PL dih-), and in the subject prefixes (INC and 2PL de?-) (Crevels 2012:251-62). The existence of such a syncretism may lead one to think that it can cause misunderstandings, but its presence in some languages, although very few, demonstrates that the different information can be retrievable by context. On the other hand, the tiny number of languages that show the syncretism may suggest that this is a situation that languages tend to change in order to avoid misunderstandings. With these reflections, I want to show that a situation in which a language has a pure syncretism between inclusive and $2 \mathrm{NSG}$, and then adds some markers to either inclusive or 2NSG, is feasible. The different way of adding markers in Savosavo-Bilua and Touo-Lavukaleve is the first sign that points to a branching hypothesis, which can be formulated as follows: Proto-Central Solomons split into two languages, which evolved differently with respect to the INC/2PL syncretism. One of them, Proto-Touo-Lavukaleve, added markers to inclusive to form the 2PL; the other, Proto-Savosavo-Bilua, added markers to 2PL to form the inclusive.

6.2 THE VELAR AND THE LATERAL DUAL MARKERS. Another fact that points to the same branching hypothesis is the difference in dual markers. We have seen in similarity 1 in 3.1 that Savosavo and Bilua share a velar dual marker, which I have reconstructed as Pre-Savosavo *-ue and Pre-Bilua *ge; while Touo and Lavukaleve share a lateral dual marker, reconstructed as Pre-Touo *Ie and Pre-Lavukaleve *le (similarity 2 of 3.2). This lateral dual marker has a reflex in the Savosavo number enclitic $=l o$.

13. Algonquian and Tanoan languages are spoken in North America, the Atlantic and Kiranti families are branches of Niger-Congo and Sino-Tibetan, respectively, and Tiwi is an Australian non-Pama-Nyungan language.

14. Itonama has only singular and plural numbers. 
Dual number forms are known to be related to the numeral 'two'. The numeral 'two' forms, shown in table 1, are Savosavo 'edo; Touo eli; Lavukaleve 'lelemal, 'lelaol, 'lelamel, 'lemal; and Bilua 'omuga, 'muga. We can clearly see that a velar consonant is present in the Bilua form and a lateral consonant in Touo and Lavukaleve, while Savosavo has an alveolar consonant. Savosavo shows a higher complexity regarding dual markers, given that the Pre-Savosavo forms are different for 2 nd person ( ${ }^{*}$ pe) and 3rd person $(*$ to). If we look at the Savosavo current forms in table 3 , we can see that the velar marker is used for all dual categories in 'la $\beta a(-\iota \mu)$, and the lateral marker $=l o$ is the dual number enclitic morpheme. In this way, the Savosavo velar and lateral markers are used for more grammatical categories than the more restricted forms 2 nd person *pe and 3rd person *to. Another fact to take into account is that, as is mentioned in 3.4 and 5.5.2, the Proto-Oceanic form for 'two' is *rua (Greenhill, Blust, and Gray 2008), which is formed by an alveolar trill or flap, which might be related to the lateral dual marker and also to Savosavo 'edo 'two'.

Touo and Lavukaleve have a dual marker related to the form of their numeral 'two', a very common occurrence cross-linguistically; this form might be an Oceanic borrowing, or the similarity to Oceanic *rua 'two' might be due to chance. The most complicated situation is with Savosavo. The velar dual marker used in Savosavo for 1DU.EXC and for all dual forms of 'laßa seems to be related to the Bilua velar dual marker and numeral 'two' ('omuga/'muga). Savosavo 'edo 'two' and number enclitic =lo might be related to Oceanic *rua, and may have been borrowed in any stage of the history of Savosavo since the Oceanic peoples arrived to the area, around 3,500 years ago. If both were borrowings, the difference in - $d o$ and -lo should suggest that the borrowings took place in different stages; hence, the different evolution of the Oceanic $/ \mathrm{r} /$.

Considering all of this, I think that a reasonable hypothesis is that a Proto-SavosavoBilua language had a numeral 'two' and dual markers with a velar consonant; this language split in two, and the remnants of these velar consonants can be observed today in Savosavo and Bilua. Savosavo evolved a 'two' form with an alveolar consonant and other dual markers (=lo, *pe, *to), and 'edo 'two' and/or =lo might be Oceanic borrowings. A Proto-Touo-Lavukaleve language would have had a form for numeral 'two' and dual markers with a lateral consonant, and these are still present in Touo and Lavukaleve. These forms with a lateral consonant might be Oceanic borrowings.

6.3 TWO MORE SIMILARITIES BETWEEN SAVOSAVO AND BILUA. Another common form in Savosavo and Bilua is the 3SG.F preform *ko, identified in similarity 1 in 3.2, and Lavukaleve also has a similar form in 3SG.F and 3DU.F distal and unspecified demonstratives $(-h-)$. However, the evidence in this case is much weaker than the much clearer relation between Savosavo and Bilua.

There is also a connection between Savosavo and Bilua in the common reconstructed preforms for 1SG, Pre-Savosavo *ani and Bilua *ani, which are based on the current Savosavo pronoun ( $a$ ' $\mathrm{i} i$ ) and the Bilua prefix ani- in several 1NSG pronouns. I have posited another possible prepronoun for Bilua (*ayai), in which case an independent identical change should have taken place in both languages. Therefore, this relation between both languages only holds if the proposal for Pre-Bilua *ani is taken into account. The 
relation would imply that a Proto-Savosavo-Bilua language had *ani as the 1SG pronoun: this form would have been retained in Savosavo with the palatalization of $/ \mathrm{n} /$ and in Bilua as a prefix in some nonsingular pronouns.

6.4 BRANCHING PROPOSAL. To sum up, the main argument for a branching hypothesis is the different treatment of the Proto-Central Solomons INC/2NSG form *me in Savosavo-Bilua and Touo-Lavukaleve, which suggests a Proto-Central Solomons language with the syncretism in its pure form, from which two languages split (ProtoSavosavo-Bilua and Proto-Touo-Lavukaleve); each of them used a different strategy so as to avoid misunderstandings due to the syncretism. Other similarities that reinforce this hypothesis are the velar and lateral dual markers, the identical form of the Savosavo 1SG pronoun a $a^{\prime} i$ and the Bilua 1st person marker ani-, and the identical 3SG.F preform *ko in Savosavo and Bilua. It is worth noting here that four similarities have been identified in 3.1 and 3.2 between two or three languages, and three of them have been cited in support of this branching (the two dual markers and the 3SG.F morpheme), while the other one (similarity 2 in 3.1) is a similarity between Savosavo and Lavukaleve regarding PreSavosavo 1PL.EXC *-ße and Pre-Lavukaleve plural marker *ba; this, however, is the weakest of all similarities because the Savosavo form is restricted only to 1PL.EXC. The arguments given here are stronger regarding a Savosavo-Bilua connection than a TouoLavukaleve relation. Furthermore, the Touo pronoun system, with its four numbers, four genders, and almost perfect symmetry (see table 6) appears to be quite different from that of the other three languages. Accordingly, I will postulate a branching hypothesis in which Proto-Touo-Lavukaleve split into its two daughter languages at an earlier time than Proto-Savosavo-Bilua did. This branching hypothesis is represented in figure 1, where the lower position of Savosavo and Bilua indicate a later split.

This branching does not fit the geographical distribution, given that Savosavo and Bilua are the easternmost and westernmost of the four languages, respectively, while Touo and Lavukaleve are in the center (see map 1), although related languages do not necessarily have to be geographic neighbors. In fact, it is very frequent that there is much dialectal fragmentation in the heartland of a family, while the periphery is less fragmented (Crowley 1997:305-6), which might suggest a Central Solomons Urheimat in the area between Rendova Island and the Russell Islands, where Touo and Lavukaleve, respectively, are spoken. However, the language map of the Solomon archipelago prior to the Austronesian expansion is virtually unknown, as is the history of the migrations of the

FIGURE 1. CENTRAL SOLOMONS FAMILY TREE

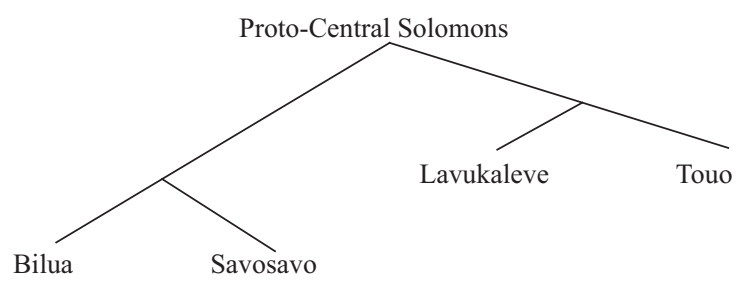


speakers of these languages and other possible extinct related languages. Consequently, I think that it does not make much sense in this case to talk about an Urheimat.

7. SUMMARY AND CONCLUSIONS. As was said in the introduction, this article has two goals. One is to provide new arguments in favor of the existence of a Central Solomons family. The point of departure for this has been a comparison of all morphemes that indicate gender, person, or number in each language. This comparison has shown some related forms, for which I have performed an internal reconstruction in each language. These internal reconstructions have provided the material for a comparison among the four languages. The main findings of this comparison have been similar forms in the 1st and 2nd person paradigms and an identical syncretism between inclusive and 2nd person nonsingular morphemes, which is represented in the four languages by the same form (*me): the rareness of this syncretism in the world's languages, together with its identical form in the four languages and the similar pronoun paradigm, have been adduced as new arguments in favor of the existence of the family that had not previously been identified in the literature.

The second goal has been to use the findings of the comparisons so as to propose a reconstruction of the pronouns of the protolanguage and a family tree. The only previous reconstruction of the pronouns of these languages was performed by Ross (2001), with much less data and for nineteen languages. Therefore, with the reconstruction performed here, I expect to improve on the one by Ross, thanks to the existence of new and extensive grammars of three of the languages and the better insights provided by concentrating on only four languages. A family tree has been proposed on the basis of some similarities found in the comparison among languages. The main argument for this branching proposal has been the different treatment of the syncretism between inclusive and 2 nd person nonsingular in Savosavo-Bilua and Touo-Lavukaleve, and this argument has been reinforced with other supporting evidence. The reconstructions and the family tree have been performed without a set of cognates and sound correspondences, however, and so these proposals must be considered highly tentative and speculative, and are made in the hope of encouraging future research.

New arguments for the existence of the family more solid than those already proposed may encourage future research on the different relations across the four languages, given that a researcher can work on more solid ground when he/she is more certain about the genetic relation of these languages. The pronoun reconstruction and branching proposal might constitute a point of departure on which to base further research that improves my proposals. This article has concentrated only on the GPN morphemes, but other aspects of grammar might provide more arguments in favor of the existence of the family and support my branching proposal or change it for a better grounded one. The extensive grammars of Savosavo (Wegener 2012), Lavukaleve (Terrill 2003), and Bilua (Obata 2003) provide invaluable material for grammatical comparison. More documentation on Touo grammar would undoubtedly expand our knowledge on the relations among the Central Solomons languages. 


\section{REFERENCES}

Campbell, Lyle. 1998. Historical linguistics: An introduction. Edinburgh: Edinburgh University Press.

Corston-Oliver, Simon. 2002. Roviana. In The Oceanic languages, ed. by John Lynch, Malcolm Ross, and Terry Crowley: 467-97. Richmond, Surrey: Curzon Press.

Crevels, Mily. 2012. Itonama. In Lenguas de Bolivia, Tomo II: Amazonía, ed. by Mily Crevels and Pieter Muysken: 233-94. La Paz: Plural Editores.

Crowley, Terry. 1997. An introduction to historical linguistics. Oxford: Oxford University Press.

. 2002. Gela. In The Oceanic languages, ed. by John Lynch, Malcolm Ross, and Terry Crowley: 525-35. Richmond, Surrey: Curzon Press.

Cysouw, Michael. 2005. Syncretisms involving clusivity. In Clusivity: Typology and case studies of the inclusive-exclusive distinction, ed. by Elena Filimonova, 73-111. Amsterdam: John Benjamins.

. 2013. Inclusive/exclusive distinction in independent pronouns. In The world atlas of linguistic structures, ed. by Matthew Dryer and Martin Haspelmath. [Accessed online at wals.info/chapter/39 on March 12, 2015.]

Dunn, Michael, and Angela Terrill. 2003. Orthographic design in Solomon Islands: The social, historical and linguistic situation of Touo (Baniata). Written Language and Literacy, 6(2):177-92.

Dunn, Michael, Angela Terrill, Ger Reesink, Robert A. Foley, and Stephen C. Levinson. 2005. Structural phylogenetics and the reconstruction of ancient language history. Science 309:2072-75.

2012. Assessing the lexical evidence for a Central Solomons Papuan family using the Oswalt Monte Carlo Test. Diachronica 29(1):1-27.

Greenberg, J. H. 1971. The Indo-Pacific hypothesis. In Current trends in linguistics, vol. 8: Linguistics in Oceania, ed. by T. A. Sebeok, 807-71. The Hague: Mouton and Co.

Greenhill, S. J., Robert Blust, and R. D. Gray. 2008. The Austronesian basic vocabulary database: From bioinformatics to lexomics. Evolutionary Bioinformatics 4:271-83. [Accessed online at language.psy.auckland.ac.nz/austronesian between February and March 2015.]

Hammarström, Harald. 2012. Pronouns and the (preliminary) classification of Papuan languages. Language and Linguistics in Melanesia, Special issue:428-539.

Heine, Bernd, and Tania Kuteva. 2004. World lexicon of grammaticalization. Cambridge: Cambridge University Press.

Hopper, Paul J., and Elizabeth Closs Traugott. 2003. Grammaticalization. Cambridge: Cambridge University Press.

Lewis, M. Paul, Gary F. Simons, and Charles D. Fennig, ed. 2014. Touo. In Ethnologue: Languages of the world, seventeenth edition. Dallas: SIL International. [Accessed online at www.ethnologue.com on June 10, 2014.]

Lynch, John, Malcolm Ross, and Terry Crowley. 2002. The Oceanic languages. Richmond, Surrey: Curzon Press.

Obata, Kazuko. 2003. A grammar of Bilua: A Papuan language of the Solomon Islands. Canberra: Pacific Linguistics.

Ross, Malcolm. 1995. The great Papuan pronoun hunt: Recalibrating our sights. In Tales from a concave world: Liber amicorum Bert Voorhoeve, ed. by Connie Baak, Mary Bakker, and Dick van der Meij, 139-68. Leiden: Leiden University. . 2001. Is there an East Papuan phylum? Evidence from pronouns. In The boy from Bundaberg. Studies in Melanesian linguistics in honour of Tom Dutton, ed. 
by Andrew Pawley, Malcolm Ross, and Darrell Tryon: 301-22. Canberra: Pacific Linguistics.

. 2005. Pronouns as a preliminary diagnostic for grouping Papuan languages. In Papuan pasts: Cultural, linguistic and biological histories of Papuanspeaking peoples, ed. by Andrew Pawley, Robert Attenborough, Robin Hide, and Jack Golson: 15-65. Canberra: Pacific Linguistics.

Terrill, Angela. 2003. A grammar of Lavukaleve. Mouton grammar library 30. Berlin: De Gruyter Mouton.

. 2006. Central Solomon languages. In Encyclopedia of language and linguistics, ed. by Keith Brown: 279-81. [Accessed online at www.sciencedirect.com on May 14, 2014.]

. 2011. Languages in contact: An exploration of stability and change in the Solomon Islands. Oceanic Linguistics 50:312-37.

Todd, Evelyn M. 1975. The Solomon language family. In New Guinea area languages and language study, vol. 1: Papuan languages and the New Guinea linguistic scene, ed. by S. A. Wurm: 805-46. Canberra: Pacific Linguistics.

Tryon, D. T., and B. D. Hackman. 1983. Solomon Islands languages: An internal classification. Canberra: Pacific Linguistics.

Wegener, Claudia. 2012. A grammar of Savosavo. Mouton grammar library 61. Berlin: De Gruyter Mouton.

Wurm, S. A. 1972. The classification of Papuan languages and its problems. Linguistic Communications 6:118-78.

- 1975. The East Papuan phylum in general. In New Guinea area languages and language study, vol. 1: Papuan languages and the New Guinea linguistic scene, ed. by S. A. Wurm: 783-804. Canberra: Pacific Linguistics.

1982. Papuan languages of Oceania. Tübingen: Gunter Narr. 